\title{
Synthesis, toxicity, biocompatibility, and biomedical applications of graphene and graphene-related materials
}

This article was published in the following Dove Press journal:

International Journal of Nanomedicine

5 May 2016

Number of times this article has been viewed

\section{Sangiliyandi Gurunathan Jin-Hoi Kim}

Stem Cell and Regenerative Biology, Konkuk University, Seoul, Republic of Korea
Correspondence: Sangiliyandi

Gurunathan; Jin-Hoi Kim

Department of Stem Cell and

Regenerative Biology, Konkuk University,

I Hwayang-dong, Kwangjin-gu, Seoul

143-70|, Republic of Korea

Tel +8224503687

Fax +82 25444645

Email gsangiliyandi@yahoo.com;

jhkim54I@konkuk.ac.kr

\begin{abstract}
Graphene is a two-dimensional atomic crystal, and since its development it has been applied in many novel ways in both research and industry. Graphene possesses unique properties, and it has been used in many applications including sensors, batteries, fuel cells, supercapacitors, transistors, components of high-strength machinery, and display screens in mobile devices. In the past decade, the biomedical applications of graphene have attracted much interest. Graphene has been reported to have antibacterial, antiplatelet, and anticancer activities. Several salient features of graphene make it a potential candidate for biological and biomedical applications. The synthesis, toxicity, biocompatibility, and biomedical applications of graphene are fundamental issues that require thorough investigation in any kind of applications related to human welfare. Therefore, this review addresses the various methods available for the synthesis of graphene, with special reference to biological synthesis, and highlights the biological applications of graphene with a focus on cancer therapy, drug delivery, bio-imaging, and tissue engineering, together with a brief discussion of the challenges and future perspectives of graphene. We hope to provide a comprehensive review of the latest progress in research on graphene, from synthesis to applications.
\end{abstract}

Keywords: biomedical applications, cancer therapy, drug delivery, graphene, graphene-related materials, tissue engineering, toxicity

\section{Introduction}

Graphene, a two-dimensional sheet of $\mathrm{sp}^{2}$-hybridized carbon atoms packed into a honeycomb lattice, has recently garnered much attention for its excellent physical and chemical properties. ${ }^{1}$ Graphene was first described as monolayer and crystalline graphitic films by the Nobel laureate Andre Geim and Konstantin Novoselov. Following this breakthrough research, researchers around the world have shown much interest in exploring the properties and applications of graphene which has been hailed as a "miracle material" 2 or a "wonder material". ${ }^{3}$ Graphene has good electrical conductivity, ${ }^{4}$ high surface area, ${ }^{5}$ high strength, ${ }^{6}$ good elastic properties, ${ }^{7}$ good thermal conductivity, ${ }^{8}$ ease of functionalization, chemical inertness, ${ }^{9}$ and gas impermeability. ${ }^{10}$ Its various applications in the fields of sensors, ${ }^{11}$ energy storage devices, ${ }^{12}$ fuel cells, ${ }^{13}$ and high-strength materials ${ }^{14}$ are remarkable. Graphene materials also have applications in the biomedical sector for therapy, ${ }^{15-17}$ diagnosis, ${ }^{18-22}$ and drug delivery, ${ }^{23-27}$ and no other material has comparable properties. Although some progress has been made in diagnosis and drug delivery, the therapeutic applications of graphene remain in their infancy. This difference in the application of graphene in the biological and nonbiological sectors is owed to the toxicity of chemically reduced graphene oxide (GO) ${ }^{28-30}$ Hence, there is an 
urgent need to identify environmentally friendly, and simple approaches to prepare biocompatible graphene materials for biomedical applications.

Although much progress has been made in various areas of graphene research, much work remains to develop applications for human welfare. Graphene and its derivatives show potential toxicity in biological systems ranging from prokaryotes to eukaryotes, depending on dosage and functionalization with various reducing and stabilizing agents. The available literature suggest that the research on graphene has been extensively growing and graphene is exploited for biological applications including bacterial killing, drug delivery, nanocarrier development, cancer therapy, and tissue engineering. However, the issue of potential toxicity arises due to overwhelming application of graphene in biomedical and non-biomedical products where unintended occupational, consumer, and environmental exposures can occur. ${ }^{31}$ The synthesis, toxicity, and applications of graphene and graphene derivatives have been discussed in different areas of research, and these materials have been reviewed recently by several research groups. ${ }^{31-41}$ In this review, we highlight the biological synthesis of graphene from a green chemistry perspective, detail its synthesis using both chemical and biological methods, and discuss its toxicity, biocompatibility, and biomedical applications in detail.

\section{Structure and properties}

Strictly speaking, the term graphene refers to a single layer of graphite. More generally, it refers to fewer than ten layers of graphite. ${ }^{42}$ Like carbon nanotubes, fullerene, graphite, and diamond, it is an allotrope of elemental carbon with $\mathrm{sp}^{2}$-hybridized carbon atoms, with partially filled $\mathrm{p}$-orbitals above and below the plane of the sheet. It is the thinnest, honeycomb lattice structure composed of carbon atoms. ${ }^{42}$ Graphene materials can be classified in two ways: based on their structure and stacking arrangement. Based on stacking arrangement, they are classified as ABAB type (Bernal stacking), ABCABC type (rhombohedral stacking), and AAA type; Raman imaging is used to determine the stacking arrangement. ${ }^{43,44}$ Graphene with no regular stacking order is classified as "turbostratic". Stacking of graphene with other materials to form hybrid materials with the desired properties for specific applications has also been attempted. Recently, Hunt et $\mathrm{al}^{45}$ reported the stacking of hexagonal boron nitride with a conducting single layer of graphene for band-gap engineering applications to form transistors and other semiconductor devices. Studies have revealed that stacking influences the properties of graphene. ${ }^{43,46,47}$
Graphene can also be classified based on edge type, as edges also play a key role in determining the properties of the material; graphene materials are divided into those with armchair motifs and those with zigzag motifs. ${ }^{48,49}$ Graphene has a carbon-carbon bond length of $0.142 \mathrm{~nm},{ }^{44}$ and it is the thinnest known material with a good strength. The high strength of graphene facilitates its application in flexible electronics and in high-strength composites. ${ }^{14,50}$ Lee et $\mathrm{a}^{51}$ estimated the Young's modulus values of single- and bi-layer graphene as $2.4 \pm 0.4$ and 2.0 $\pm 0.5 \mathrm{TPa}$, respectively, using Raman spectroscopy. The Young's modulus of graphene has also been determined using molecular dynamics. ${ }^{52}$ The high electrical conductivity is another important feature of graphene. ${ }^{53,54}$ Graphene also has excellent thermal conductivity, gas permeability, ${ }^{55,56}$ and high surface area. ${ }^{57-60}$ The ballistic transport ${ }^{54}$ and the quantum hall effect ${ }^{61}$ of graphene are also interesting features that offer immense potential for the applications of graphene-based materials. Unique features such as chemical inertness and ease of functionalization aid in the development of these materials for biomedical applications. ${ }^{62}$ Pure graphene is reported to be biocompatible. $^{63}$

\section{Synthesis of graphene}

Several research groups have thoroughly reviewed the synthesis of graphene. ${ }^{64-69}$ However, the synthesis of graphene using biological systems has not yet been explored. Therefore, this review focuses on summarizing the synthesis of graphene using biological systems. Generally, graphene synthesis is classified in two categories: top-down and bottom-up. The former approach employs exfoliation of a layer of graphene from a graphitic material. The latter approach involves the building up of graphene using carbonbased materials. The bottom-up approach is simple, but it produces material with relatively more defects than the topdown approach. Top-down approaches separate the stacked sheets by disrupting the van der Waals forces that hold the sheets together. Damaging of the sheets during the exfoliation process and reagglomeration of the separated sheets are some of the disadvantages of the top-down technique. The other disadvantage is that graphite, the precursor, is scarce. The bottom-up approach, on the other hand, requires very high temperature. Top-down approaches include micromechanical exfoliation, electrochemical exfoliation, electrochemical and chemical reduction strategy, exfoliation of graphite oxide, solvent-based exfoliation, arc discharge, and unzipping of carbon nanotubes. The bottom-up approaches include epitaxial growth on $\mathrm{SiC}$, chemical vapor deposition, substrate-free method, and carbonization. Micromechanical 
exfoliation is a very simple and commonly used technique for investigation of the fundamental properties of graphene. It involves the use of a scotch tape or any other mechanical means to peel layers of graphene from graphite. It is a slow and labor-intensive technique and is not suited for commercial applications..$^{70,71}$ Electrochemical exfoliation is another simple technique for the synthesis of graphene. ${ }^{72,73}$ Acids are used as surfactants in this process, and so this technique may not be ideal for the synthesis of graphene for biomedical applications. ${ }^{74-76}$ In addition, the surfactants are very difficult to remove. The availability of a biocompatible, nontoxic surfactant for use in this technique will greatly aid in developing better methodologies for synthesis. Coupling of sonication with intercalation and solvent-assisted thermal exfoliation has also been reported for the synthesis of GO. Expanded graphite formation, which involves treating graphite with strong acids coupled with sonication or thermal treatment, is another physiochemical option for the synthesis of graphene. ${ }^{77}$ Exfoliation of graphite oxide is another method for the synthesis of graphene. ${ }^{78,79}$

To date, several methods are available for the synthesis of graphene and its derivatives, including mechanical exfoliation, ${ }^{1}$ epitaxial growth, ${ }^{80}$ chemical vapor deposition, ${ }^{81,82}$ unzipping of carbon nanotubes, ${ }^{83}$ exfoliation of GO, ${ }^{84}$ liquid-phase exfoliation of graphite, ${ }^{85-87}$ ion intercalation and exfoliation, ${ }^{88,89}$ hydro-/solvo-thermal synthesis, ${ }^{90}$ chemical routes, ${ }^{91}$ photocatalysis,${ }^{92}$ photodegradation, ${ }^{93}$ and electrochemical exfoliation. ${ }^{75}$ All of these methods can produce highly crystalline graphene but are unsuitable for mass production. ${ }^{94}$

Hummer's method is a common method for the oxidation of graphite..$^{55}$ The GO formed is then reduced to form a reduced graphene oxide (rGO). The reduction of GO can be performed with different chemical and biological reducing agents. ${ }^{96,97}$ The most commonly used chemical reducing agents for the reduction of GO are hydrazine, ${ }^{98-101}$ sodium borohydride, ${ }^{102-104}$ Lawesson's reagent, ${ }^{105}$ and thiourea. ${ }^{106,107}$ Chemical reduction seems to be a very simple approach; however, it generates a graphene-like film containing low $\mathrm{C}$ : $\mathrm{O}$ ratio and a considerable quantity of residual functional groups, which leads to highly resistive film. ${ }^{108-110}$

However, chemical reducing agents are toxic or explosive, resulting in challenges for large-scale production. ${ }^{111}$ The graphene resulting from chemical approach has limited solubility or even undergoes irreversible agglomeration during preparation in water and most organic solvents, unless capping reagents are used, owing to the strong $\pi-\pi$ stacking tendency of rGO sheets. ${ }^{11-117}$ The most commonly used chemical reducing agents are anhydrous hydrazine, hydrazine monohydrate, sodium borohydride, and hydrogen sulfide, which are highly toxic and harmful to living organisms and the environment. ${ }^{113,115-117}$ To enhance the solubility and prevent aggregation problems, several polymers or surfactants have been tested, such as poly(sodium 4-styrenesulfonate), alkaline agents, poly( $N$-vinyl-2-pyrrolidone), poly(allylamine), ${ }^{91,118-120}$ betamercaptoethanol, ${ }^{121}$ dithiothreitol, ${ }^{122}$ and triethylamine. ${ }^{123}$

\section{Synthesis of graphene using biomolecules}

Biological molecules have been used for synthesis of graphene or reduction of GO due to their easy availability. The synthesis of graphene as a single carbon layer from graphite using thermal, chemical, or electrical treatments is slightly different from that of $\mathrm{rGO}$ which is prepared from reduction of GO by chemical or biological methods. The reduction of GO differs based on the reducing agents used, and different reducing agents will produce various $\mathrm{C}: \mathrm{O}$ ratios and chemical compositions. Recently, usage of biological materials for synthesis of nanoparticles (NPs) has garnered much attention due to their low energy requirements, environmentally friendly nature, dependability, cost-effectiveness, scalability, stability, and availability of the required solutions at high densities, compared with chemical synthesis. ${ }^{113}$ Similar approaches have been exploited for the synthesis of graphene using proteins, peptides, bacteria, fungi, plants, and others.

For example, Salas et al ${ }^{124}$ initially proposed "green" reduction of GO via bacterial respiration. Wang et al ${ }^{125} \mathrm{dem}$ onstrated reduction of GO using respiration of Shewanella cells. Interestingly, microbially reduced graphene exhibits excellent electrochemical properties. Subsequently, several laboratories showed synthesis of graphene or reduction of GO using several microorganisms including baker's yeast, ${ }^{114}$ Escherichia coli, ${ }^{126,127}$ Escherichia fergusonii, ${ }^{128}$ Pseudomonas aeruginosa, ${ }^{121}$ Bacillus marisflavi, ${ }^{116}$ and Ganoderma spp. ${ }^{129}$ In addition to bacterial systems, several studies have shown usage of plant extracts for reduction of GO. Plants and plant extracts have received much attention for reduction of $\mathrm{GO}$ as a suitable alternative to chemical procedures and physical methods. ${ }^{130}$ Extracts from plants may act as both reducing and capping agents in NP synthesis. ${ }^{99,131} \mathrm{~A}$ few studies have demonstrated reduction of GO using plant extracts including leaf extracts of Colocasia esculenta and Mesua ferrea, ${ }^{130}$ Ginkgo biloba extract, ${ }^{129}$ leaf extracts of cherry, Magnolia, Platanus, persimmon, pine, maple, and Ginkgo, ${ }^{132}$ and extracts of Pulicaria glutinos $a^{133}$ and Salvadora persica. ${ }^{134}$ Therefore, plant extracts 
could be a potential alternative resource for reducing and stabilizing agents for the synthesis of graphene. A number of studies have also reported GO reduction using various biomolecules, such as ascorbic acid, ${ }^{135}$ amino acids, ${ }^{98}$ glucose, ${ }^{136,137}$ bovine serum albumin, ${ }^{138}$ melatonin, ${ }^{139}$ humanin, ${ }^{140}$ enhanced green fluorescent protein, ${ }^{111}$ and resveratrol, a phenolic compound derived from grapes. ${ }^{113}$ In particular, use of recombinant proteins for the synthesis of graphene or NPs would save energy and time in downstream processing, and compared to bacterial reduction, this method does not pose the danger of introducing endotoxins. ${ }^{141,142}$ However, most of these procedures limit the use of graphene materials for biological applications. Chemical reduction methods, in addition to polluting the environment, are toxic to prokaryotic/eukaryotic systems. Not only is biological reduction of $\mathrm{GO}$ inexpensive, but it also presents fewer burdens, requires less time for reduction process, and most importantly, is nontoxic and biocompatible. Not only is biological reduction of GO inexpensive, but it also presents fewer burdens, requires less time for reduction process, and most importantly, is nontoxic, biocompatible, and high yield. However, one of the challenges posed by biological methods is the purification of graphene from the biomass. Also, they require a number of centrifugation processes. To avoid centrifugation, we can use extracellular-mediated reduction of GO, which is very simple.

Several reports have been published on the detrimental effects of graphene. Schinwald et al ${ }^{143}$ reported the inflammogenic effects of graphene in both the lung and the pleural space. However, neither the procedure followed for graphene synthesis nor the functional groups available on the graphene surface were discussed. Whether the graphene molecule alone caused the toxicity or the functional groups formed during synthesis led to toxicity is unclear. In another similar study, the effect of the shape of graphene on cytotoxicity has been reported. Increased lactate dehydrogenase (LDH) release, reactive oxygen species (ROS)-mediated oxidative stress, and caspase 3-mediated apoptosis on exposure to graphene in neural pheochromocytoma-derived PC12 cells have been reported. ${ }^{144}$ Thus, it remains unclear whether graphene is safe or toxic. ${ }^{145}$

\section{Toxicity of graphene in prokaryotic cells}

Nanomaterials are considered to be powerful tools for nanotechnological applications in industry, cosmetics, and health care. In general, NPs appear to be a double-edged sword because they have both beneficial and adverse effects, depending on the context of application. The toxic effects of graphene can be influenced by physicochemical properties such as size and distribution, surface charge, surface area, layer number, lateral dimensions, surface chemistry, purity, particulate state, surface functional groups, and shape..$^{31,146,147}$ The mechanisms by which GO and rGO nanowalls show toxicity to $E$. coli and Staphylococcus aureus bacteria were demonstrated by Akhavan and Ghaderi ${ }^{28}$ and $\mathrm{Hu}$ et al. ${ }^{148}$ They demonstrated that both GO and rGO are effective as antibacterial agents. Subsequently, many research laboratories have investigated the potential toxicity of GO and rGO against several bacterial species. For instance, GO and rGO have been reported to enhance bacterial toxicity through enhanced production of ROS in P. aeruginosa ${ }^{121}$ and E. coli, ${ }^{127}$ and cause loss of membrane integrity. ${ }^{125}$ Interestingly, Akhavan and Ghaderi ${ }^{126}$ reported that $E$. coli can reduce GO to bactericidal graphene in a self-limiting manner. Among various types of nanomaterials including graphite, graphite oxide, GO, and rGO, GO showed the strongest antibacterial activity under similar concentrations and incubation conditions, followed by rGO, graphite, and graphite oxide. ${ }^{30}$ Further, they showed that the antibacterial mechanism included initial cell deposition on graphene-based materials, membrane stress caused by direct contact with sharp nanosheets, and ensuing superoxide anion-independent oxidation. In another report, Liu et $\mathrm{al}^{149}$ showed that the antibacterial activity of GO sheets toward $E$. coli cells was dependent on the lateral size, time, and concentration. Graphene effectively inhibited the growth of Gram-negative E. coli and Grampositive Bacillus subtilis at a concentration of $1 \mathrm{mg} / \mathrm{mL}{ }^{150}$ Li et $\mathrm{ll}^{151}$ investigated a large-area monolayer graphene film manipulated by charge transfer from a conductor $(\mathrm{Cu})$, a semiconductor $(\mathrm{Ge})$, or an insulator $\left(\mathrm{SiO}_{2}\right)$. Graphene films on $\mathrm{Cu}$ and $\mathrm{Ge}$ inhibited the growth of bacteria by membrane damage and destroying membrane integrity. Figure 1 shows the antibacterial activity of both GO and $\mathrm{rGO}$ in $P$. aeruginosa (Gram negative) and S. aureus (Gram positive).

Recently, graphene has been used as an antibacterial agent in various nanomaterials. For example, Ma et $\mathrm{al}^{152}$ reported that silver-modified GO nanosheets (Ag-GO) exhibited superior antibacterial activity toward $E$. coli, due to the synergistic effect of GO and Ag NPs. An Ag-GO nanocomposite displayed high biocidal activity with a minimum inhibitory concentration ranging from 2.5 to $5.0 \mu \mathrm{g} / \mathrm{mL}^{153}$ and better reduction of cell viability than GO. ${ }^{154}$ Both Ag NP and Ag-GO samples showed significant antibacterial activity against both Gram-negative and Gram-positive bacteria; in particular, activity was stronger against Gram-negative than against Gram-positive bacteria. ${ }^{155}$ Ag NPs anchored on rGO modified with polyethylenimine showed higher antibacterial activity than free Ag NPs. ${ }^{156}$ 


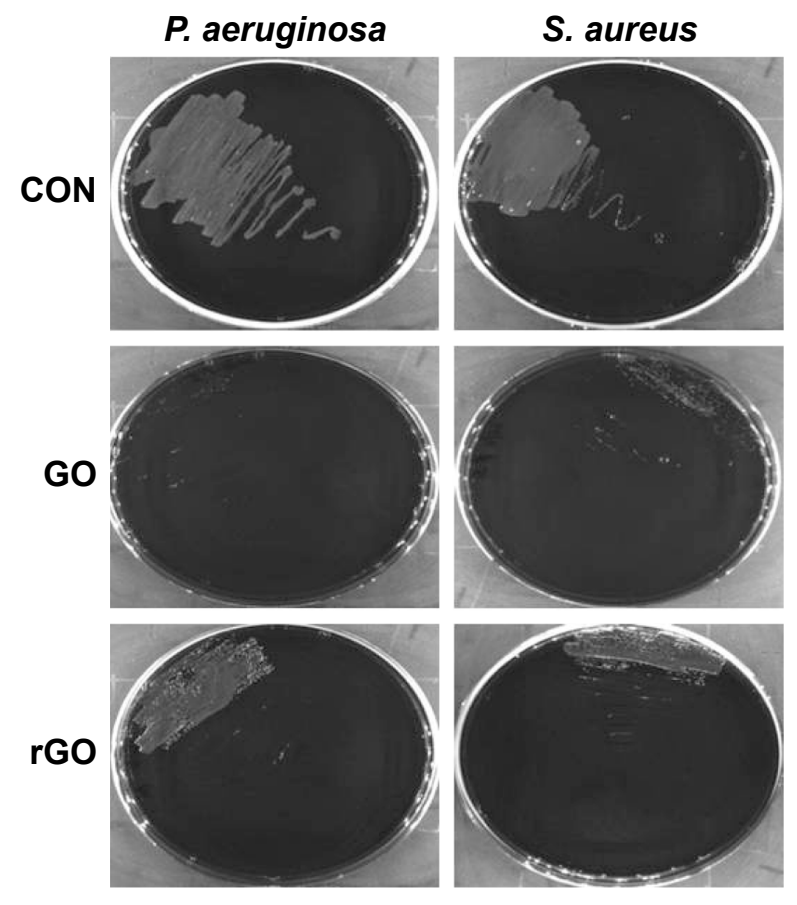

Figure I Antibacterial activity of GO and GO reduced by Evolvulus alsinoides leaf extract in Pseudomonas aeruginosa and Staphylococcus aureus.

Notes: Cells were incubated with GO and rGO $(100 \mu \mathrm{g} / \mathrm{mL})$ separately. Samples were withdrawn at 4 hours and streaked on nutrient agar plates and incubated at $37^{\circ} \mathrm{C}$ for 24 hours. The differential toxicity of GO and rGO was observed both in Gram-negative and Gram-positive bacteria.

Abbreviations: CON, control; GO, graphene oxide; rGO, reduced graphene oxide.

The functional differences between $\mathrm{GO}$ and $\mathrm{Ag}-\mathrm{GO}$ could be caused by various physical and chemical properties, such as the size and thickness of the sheets, the oxidation ratio, and the solubility. ${ }^{153} \mathrm{Ag}$-GO NPs may cause cell death by the following mechanisms: (i) GO could adhere to or wrap around E. coli through hydrogen bonds between the lipopolysaccharides of the bacteria and the oxygenated functional groups of GO. ${ }^{107,152,155}$ (ii) GO could prevent uptake of nutrients from the surroundings while increasing the interaction between $\mathrm{Ag}$ NPs and the bacteria, ${ }^{152}$ after which Ag NPs favor disruption of the bacterial membrane, leading to inhibition of respiration and replication of bacteria and eventually to cell death. ${ }^{133,155-159}$ (iii) The antibacterial effect of Ag-GO NPs could be caused by the "capturing-killing process", in which Ag-GO NPs contribute to the deposition of bacteria and increase the contact between the cells and the as-synthesized Ag NPs. ${ }^{160}$

\section{In vitro toxicity of graphene in eukaryotic cells}

The toxic potential is determined by many factors, among which the interaction between NPs and biological samples is the most crucial. ${ }^{161}$ In addition, toxicity of graphene in eukaryotic cells depends on several factors, such as chemical composition, size, surface, shape, use of reducing agents for functionalization of graphene, functional groups, charges, coatings, structural defects of graphene, and dissolving media. Therefore, different studies have reported differing results for NP toxicity. However, general toxicity in eukaryotic cells has been demonstrated. Zhang et al ${ }^{144}$ described that the toxic effect of graphene and single-walled carbon nanotubes (SWCNTs) in neural pheochromocytoma-derived PC12 cells was concentration and shape dependent. Interestingly, low concentrations of graphene induced stronger metabolic activity than SWCNTs. LDH levels were found to be significantly increased on exposure to SWCNTs than graphene. Lower concentration of GO has no significant effect on cellular uptake, morphology, viability, mortality, and membrane integrity. ${ }^{162} \mathrm{Hu}$ et al ${ }^{163}$ reported that the effect of GO was largely attenuated by incubation with $10 \%$ fetal bovine serum; the reason was found to be that GO has extremely high protein adsorption ability. Functionalization of graphene by using different reducing agents plays an important role in toxicity. For instance, pristine graphene was shown to cause high oxidative stress by accumulation on the cell membrane, whereas carboxyl-functionalized hydrophilic graphene was not toxic even after internalized by cells. ${ }^{164}$ The toxicity of oxidized graphene nanoribbons coated with (1,2-distearoyl-sn-glycero-3-phosphoethanolamine$N$-[amino(polyethylene glycol)]) (O-GNRs-PEG-DSPE) was evaluated in four cell lines (HeLa, MCF-7, SKBR3, and NIH3T3) using six different biochemical and cellular assays. The results indicated that O-GNRs-PEG-DSPE have dose- and time-dependent differential cytotoxic effects on the four different cell lines. Among various cell lines, HeLa cells exhibited greater toxicity compared to the other cell lines. ${ }^{165}$ However, purified GO showed no significant cytotoxicity in epithelial lung carcinoma cells up to $100 \mu \mathrm{g} / \mathrm{mL}$, and no inflammation or granuloma formation (up to $50 \mu \mathrm{g} /$ animal dose exposure) in vivo. ${ }^{166}$ Lammel et al ${ }^{167}$ showed that GO has a dose-dependent toxic effect through plasma membrane damage, that is, loss of plasma membrane structural integrity, which was associated with a strong physical interaction of GO with the phospholipid bilayer. Further, they showed that GO could penetrate the plasma membrane, resulting in altered cell morphology and an augmented number of apoptotic cells. Gurunathan et al ${ }^{116}$ examined bacterially reduced GO in MCF-7 cells, and found that both GO and bacterially reduced GO exhibit toxicity to MCF-7 cells in a dose-dependent manner. Similarly, GO reduced by extracts of Ganoderma spp. showed similar toxicity in MDA-MB-231 human breast cancer cells. ${ }^{129} \mathrm{Qu}$ et al ${ }^{168}$ demonstrated that 

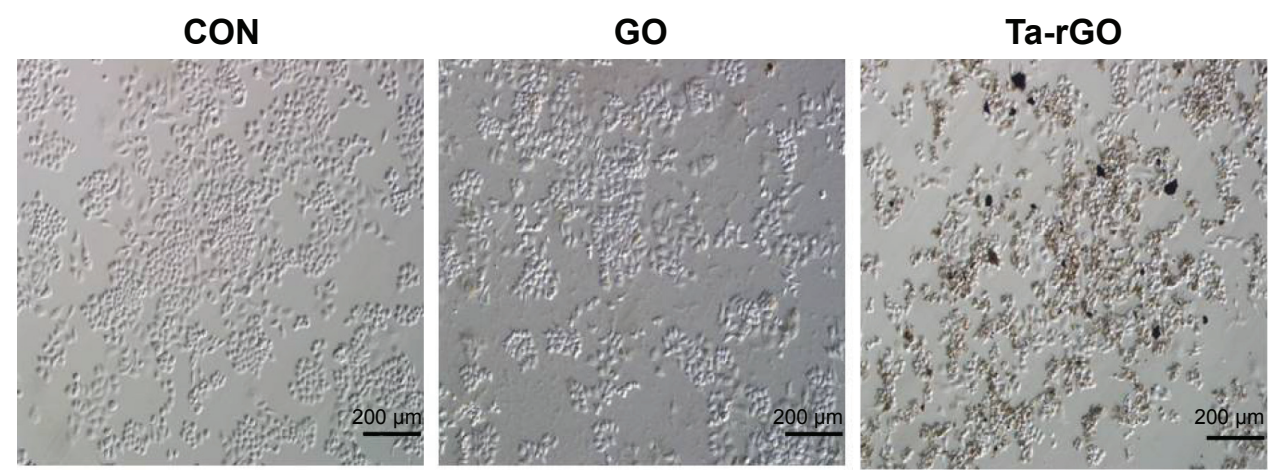

Figure 2 Toxicity of GO and Ta-rGO to human ovarian cancer cells.

Notes: The morphology of human ovarian cancer cells was determined after 24 hours of exposure to GO and Ta-rGO (50 $\mu \mathrm{g} / \mathrm{mL})$. Images were captured by interference contrast light microscopy.

Abbreviations: CON, control; GO, graphene oxide; rGO, reduced graphene oxide; Ta-rGO, GO reduced by Typha angustifolia leaf extract.

GO induced necrotic cell death in macrophages by activation of toll-like receptor 4 signaling and partly via autocrine production of tumor necrosis factor alpha. Wang et al ${ }^{169}$ studied the effects of SWCNTs and GOs using various biochemical assays including cell viability, autophagy induction, and lysosome destabilization in murine peritoneal macrophages, and found that GO molecules were more potent than SWCNTs. Conversely, graphene quantum dots (GQDs) showed low toxicity in HeLa cells. ${ }^{170}$ Jaworski et al ${ }^{171}$ studied the toxicity of both GO and rGO in U87 platelets, U118 glioma cells, and in vivo. The in vitro results indicated that $\mathrm{GO}$ and $\mathrm{rGO}$ enter glioma cells and show dose-dependent toxicity; rGO was more toxic than GO. In vivo studies suggest that the mass and volume of tumors were reduced after injection of GO and rGO. RAW 264.7 macrophages treated with pristine graphene were found to show increased ROS generation and impairment of mitochondrial membrane potential and cell death by inducing MAP kinases and transforming growth factor-beta-related signaling pathways. ${ }^{172,173}$ Recently, we found that resveratrol-reduced GO induced more toxic effects than GO in human ovarian cancer cells by increasing LDH release, ROS generation, activation of caspase-3, and DNA fragmentation. ${ }^{113}$ For example, GO reduced by Typha angustifolia leaf extract induced apoptosis by causing morphological changes (Figure 2).

\section{In vivo toxicity of graphene}

In vivo toxicity assessment is an essential part of drug delivery research. Graphene could be beneficial or toxic. A biocompatibility study was performed using mice, in which no toxicity was detected in mice exposed intravenously to GO at low $(0.1 \mathrm{mg})$ and medium $(0.25 \mathrm{mg})$ doses, whereas a high dose of GO $(0.4 \mathrm{mg})$ resulted in chronic toxicity. ${ }^{125}$ Another study demonstrated that the functional aspects differed with size; larger GO particles of 1-5 $\mu \mathrm{m}$ and $110-500 \mathrm{~nm}$ accumulated in the lungs, whereas smaller particles were retained by the liver. ${ }^{174}$ One study suggested that a 24-hour treatment with nanographene sheets led to accumulation in the reticuloendothelial system (RES) of tumor cells; however, no significant toxicity was observed. In contrast, graphene nanosheets induced pulmonary inflammation, thromboembolism, and immune responses in the lungs of C57BL/6 mice after intravenous administration of $1 \mathrm{mg} / \mathrm{kg}$ body weight. ${ }^{175}$ On the other hand, nanographene sheets accumulated initially in the RES, liver, and spleen, and later, they were cleared and induced no toxicity at a dose of $20 \mathrm{mg} / \mathrm{kg} .{ }^{176} \mathrm{In}$ another study, various forms of graphene, such as solutions of aggregated graphene, pluronic-dispersed graphene, and GO, were injected directly into the lungs of mice. GO induced mitochondrial generation of ROS, activated inflammatory and apoptotic pathways, and also resulted in severe and persistent lung injury, whereas the mice treated with aggregated graphene and dispersed graphene showed no obvious lung injury. ${ }^{177}$ Graphene nanosheets induced cell injury by increasing the levels of various cytokines particularly interleukin-33 and its soluble receptor. ${ }^{175} \mathrm{~A}$ study of the in vivo behavior of dextran-coated GO (GO-DEX) showed that GO-DEX also mainly accumulates in the RES organs at early time points after intravenous injection, and could be gradually excreted over time. ${ }^{178}$ Pristine GO induces pulmonary edema and granuloma formation in the lung. ${ }^{.78,179}$

Japanese white rabbits injected intravitreally with GO at concentrations of $0.1,0.2$, or $0.3 \mathrm{mg}$ showed no clinical evidence for ocular changes, and GO had a negligible influence on both the intraocular pressure and eyesight in treated animals. ${ }^{180} \mathrm{~A}$ study in which mice were intravenously injected with polyethylene glycol-treated nanographene oxide (NGO-PEG) at a dose of $20 \mathrm{mg} / \mathrm{kg}$ showed that the 
NGO-PEG-treated groups at different times postinjection appeared to be normal compared with the control groups and also found no noticeable organ damage or inflammation. ${ }^{181}$ In addition, short-term exposure to GO-DEX did not induce obvious toxicity in treated animals. ${ }^{178}$ The toxicity of graphene depends on surface modifications in vivo. In order to address this issue, Yang et $\mathrm{a}^{27,33,176}$ performed time-dependent studies using graphene and PEGylated graphene. One hour after an intravenous injection with $20 \mathrm{mg} / \mathrm{kg}$, polyethylene glycol (PEG)-graphene nanosheets were distributed in many different organs, and after 3 days, PEG-graphene was found mainly in the RES, including the spleen and liver. After 90 days, the PEG-graphene nanosheets produced neither death nor a significant decrease in body weight in the mice. In addition, no significant changes in blood biochemistry or hematology were observed. Furthermore, the liver and kidney functional markers including alanine aminotransferase, aspartate aminotransferase, and alkaline phosphatase (ALP) showed no changes. The ratio of albumin and globulin, the urea levels in the blood, and all hematology markers were also unchanged. ${ }^{27,33,176}$ Singh et al ${ }^{182}$ found that GO could induce extensive pulmonary thromboembolism in mice. Few-layer graphene with diameters up to $25 \mu \mathrm{m}$ induced high levels of inflammation in the mouse lung. ${ }^{143}$ The long-term in vivo bio-distribution of intravenously injected nanographene oxide (NGO) functionalized with poly(sodium 4-styrenesulfonate) was systematically examined over 6 months. The evidence from blood biochemistry and histological examinations showed that the NPs mainly accumulated in the lung, liver, and spleen, and caused acute liver injury and chronic inflammation in the accumulated organs. ${ }^{183}$ Zhang et al ${ }^{184}$ demonstrated the behavior of mice after short- and long-term administration of rGO. Mice that received a high dose of small or large rGO nanosheets showed little change in exploratory, anxiety-like, or learning and memory behaviors.

\section{Biocompatibility of graphene}

Biocompatibility refers to the ability of materials to interact with cells, tissues, or the body without causing harmful effects. Recently, the usage of graphene in stem cell research has been increased due to its unique properties. ${ }^{185}$ Liu et al ${ }^{186}$ fabricated efficient glucose biosensors through covalent attachment of carboxyl acid groups to GO sheets at the amine residue of GO. The biosensors showed not only good reproducibility and good storage stability but also good adhesion; differentiation of ARPE-19 cells on the GO film was visualized after 72 hours of culture. GO-polyaniline and graphene-polyaniline hybrid papers showed much higher biocompatibility with the mouse fibroblast cell line L929 than parent papers such as GO or graphene. ${ }^{187}$ Park et $\mathrm{al}^{188}$ fabricated a strong and biocompatible free-standing paper composed of Tween-20 and chemically reduced GO. It showed excellent stability in water and was nontoxic to three mammalian cell lines, Vero cells, embryonic bovine cells, and Crandell-Rees feline kidney cells. Graphene/ chitosan hybrid films can repair tissue and improve tissue functions. ${ }^{189}$ Graphene conjugated with heparin chains preserved their anticoagulant activity, and showed a much enhanced anti-factor Xa activity of $29.6 \mathrm{IU} / \mathrm{mL}$ compared with pristine GO (1.03 IU/mL). ${ }^{190}$ Dextran-reduced GO showed significant biocompatibility with HeLa cells, a cervical cancer cell line. ${ }^{115}$ A study by Lee et al $^{191}$ demonstrated that graphene- and GO-coated substrates accelerated mesenchymal stem cell (MSC) adhesion, proliferation, and differentiation. Human adenocarcinoma HT-29 cells grown on GO-coated glass slides showed morphological changes and cell enlargement and spreading. Thus, several pieces of evidence support that GO shows promise as a supporting material for cell attachment, growth, and proliferation. ${ }^{192}$

Graphene and GO can support culture of mouse induced pluripotent stem cells (iPSCs) and allows for spontaneous differentiation. iPSCs cultured on a graphene surface exhibited normal cell adhesion and proliferation, whereas iPSCs cultured on a GO surface adhered and proliferated at a faster rate. ${ }^{193}$ Mouse embryonic fibroblast cells treated with microbially reduced GO showed significantly strong viability, and cells grown on plates coated with microbially reduced GO exhibited significant attachment and a higher rate of survival than those treated with hydrazine-reduced GO ${ }^{194}$ Similarly, mouse embryonic fibroblast cells treated with trimethylamine-reduced GO showed increased number and significant attachment. ${ }^{123} \mathrm{GO}$ reduced by spinach leaf extract enhanced ALP activity in mouse embryonic fibroblast cells. ${ }^{194}$ Similarly, GO reduced by G. biloba extract showed significant biocompatibility and increased ALP activity in human breast cancer cells compared to GO.${ }^{117}$ Conversely, Yang et $\mathrm{al}^{195}$ found that GO could effectively promote dopamine neuron differentiation and further enhancement of dopamine neuron-related gene expression compared with untreated cells. The toxicity or biocompatibility depends on the functionalization of graphene, which can reduce its toxic effects. For example, functionalization of graphene with PEG can minimize oxidation. After 90 days of treatment, histological and hematological analysis showed no considerable toxicity in mice treated with PEGylated graphene 

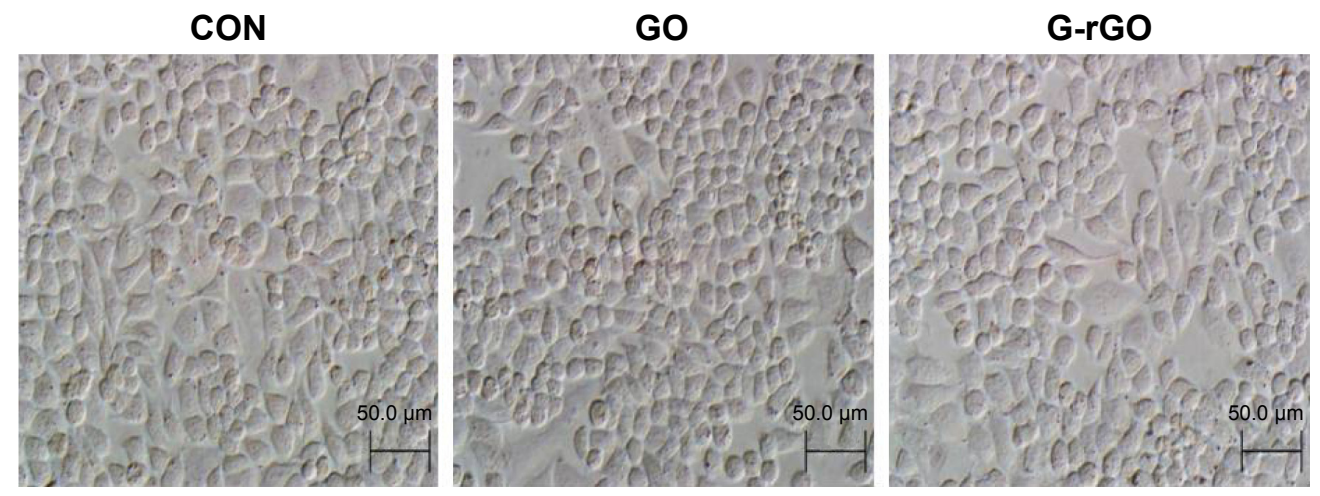

Figure 3 Biocompatibility of GO and G-rGO with human ovarian cancer cells.

Notes: Human breast cancer cells were treated with GO and G-rGO $(50 \mu \mathrm{g} / \mathrm{mL})$ for 24 hours, and then the cells were imaged by light microscopy. Representative microscopic images of GO- and G-rGO-treated cells $(50 \mu \mathrm{g} / \mathrm{mL})$.

Abbreviations: CON, control; G-rGO, glutathione-reduced GO; GO, graphene oxide; rGO, reduced graphene oxide.

$(20 \mathrm{mg} / \mathrm{kg}) \cdot{ }^{176}$ Recently, Dubey et a ${ }^{196}$ reviewed the detailed role of graphene in bone tissue engineering. Graphene-based materials enhance stem cell attachment and growth for osteogenic differentiation. ${ }^{196,197}$ Several studies have shown that graphene-coated materials are nontoxic and enhance the attachment and proliferation of fibroblasts, osteoblasts, and MSCs. ${ }^{191,198-202}$ Interestingly, Li et al ${ }^{203}$ found that graphene can promote neurite sprouting and outgrowth compared to tissue culture plates made of polystyrene. Recently, we found that glutathione-reduced GO showed biocompatibility with human ovarian cancer cells (Figure 3).

\section{Biomedical applications of graphene}

Recently, graphene derivatives such as GO and rGO have been shown to exhibit a compatible combination of chemical and physical properties that make them promising candidates for biomedical applications including anticancer therapy, photothermal therapy (PTT), photodynamic therapy (PDT), drug delivery, gene transfection, biosensing and imaging, and tissue engineering. ${ }^{40}$ Cancer is one of the most prevalent diseases globally, and one of the biggest challenges for humanity. Nanotechnology shows excellent promises to attack cancer cells more specifically and effectively, and to reduce undesired side effects. ${ }^{41}$ Robinson et $\mathrm{al}^{204}$ developed a photothermal agent using nanosized rGO (nano-rGO) sheets with high near-infrared (NIR) light absorbance and high photothermal efficiency at a low cost. The single-layered nano-rGO sheets were $\sim 20 \mathrm{~nm}$ in average lateral dimension, containing amphiphilic PEGylated polymer chains and provided stability in biological solutions; they exhibited sixfold higher NIR absorption than nonreduced, covalently PEGylated nanosized GO. Arg-Gly-Asp motif conjugated to nano-rGO enhanced selective cellular uptake and photoablation in U87MG cancer cells. ${ }^{204,205}$ Folic acid-conjugated GO-loaded nanocarriers with photosensitizers significantly increased the accumulation of chlorin e6 (Ce6) and photodynamic efficacy in tumor cells. ${ }^{204,205}$ Subsequently, Tian et al ${ }^{206}$ reported that the photosensitizer molecule, Ce6, can be loaded on PEG-functionalized GO via supramolecular $\pi-\pi$ stacking. The GO-PEG-Ce6 complex obtained shows excellent water solubility, generation of cytotoxic singlet oxygen, and enhanced intracellular trafficking under light excitation for PDT using photosensitizers. The newly designed GO-PEG-Ce6 complex causes significant cancer cell photodynamic destruction compared to free Ce6. The synergistic effect of chemo-photothermal therapy using doxorubicin (DOX)-loaded NGO-PEG offers higher therapeutic efficacy than chemotherapy or PTT alone. ${ }^{207}$ A multifunctional nanocomposite named GO-PEG-FA/Gd/ DOX-loaded anticancer drug DOX hydrochloride via $\pi-\pi$ stacking and hydrophobic interactions exhibited superior tumor targeting and imaging efficiency over free $\mathrm{Gd}^{3+}$ and also exhibited a cytotoxic effect in cancer cells. ${ }^{32} \mathrm{GO}$ functionalized with polyethylenimine and polyethylene glycol (GO-PEI-PEG) showed a significant regression in tumor growth and tumor weight after plasmid-based Stat3 siRNA was delivered by GO-PEI-PEG treatment. ${ }^{208}$ The bioactive molecule, paclitaxel, enhanced by the combination of GO with SWCNTs, caused toxicity to lung cancer cells through activation of ROS and MAP kinase. ${ }^{209}$ Intravenous administration of protein-assisted fabricated nano-rGO in tumor-bearing mice showed rapid and significant photoacoustic signal enhancement in the tumor region, indicating its excellence for passive targeting and photoacoustic imaging. In addition, the photothermal effect of nano-rGO could efficiently destroy cancer cells. ${ }^{210}$ Reduced graphene oxide 
nanomesh functionalized with polyethylene glycol, arginineglycine-aspartic acid-based peptide, and cyanine 7 (rGONMPEG-Cy7-RGD) resulted in an ultraefficient PTT (100\% tumor elimination 48 hours after intravenous injection of an ultralow concentration [10 $\mu \mathrm{g} / \mathrm{mL}]$ of rGONM-PEG-Cy7RGD followed by irradiation with an ultralow laser power $\left[0.1 \mathrm{~W} / \mathrm{cm}^{2}\right]$ for 7 minutes). ${ }^{211}$ Yang et $\mathrm{al}^{212}$ demonstrated the use of epidermal growth factor receptor antibody-conjugated NGO-PEG containing epirubicin for tumor targeting, and that triple therapeutics showed synergistic effects and also enhanced the local drug concentration (6.3-fold). The combination of triple therapeutic agents significantly suppressed tumor formation and enhanced mouse survival time. Kim et $\mathrm{al}^{213}$ found that DOX-loaded $\mathrm{rGO}$ functionalized with polyethylenimine and PEG could escape from endosomes after cellular uptake by photothermally induced endosomal disruption and the proton sponge effect. GO injection not only suppressed tumor progression but also enhanced cell death, autophagy, and immune responses in immunocompetent mice bearing CT26 colon tumors. ${ }^{214}$ Reduced GO nanosheets decorated with mesoporous silica shells have been developed for use in assisted spatiotemporally controlled chemo-photothermal synergistic cancer therapy; they can generate heat under NIR irradiation, and can kill cancer cells very efficiently through the hypothermia effect. ${ }^{215}$

Drug delivery systems aim to localize delivery of therapeutic agents, in which GO is predominantly used because it can create barrier layers in multilayer thin films, trapping molecules of interest for controlled release. ${ }^{216} \mathrm{NGO}-\mathrm{PEG}$ has been used as a nanocarrier for delivery of water-insoluble aromatic anticancer drugs into cells. The NGO-PEG loaded with SN38 exhibited high cytotoxicity for HCT-116 cells, 1,000-fold more potent than CPT-11. ${ }^{217}$ Targeted delivery of chemical drugs into cells was achieved using Rituxan (a $\mathrm{CD}^{20+}$ antibody) conjugated to NGO-PEG. ${ }^{26}$ The release of the drug from the GO surface is dependent on $\mathrm{pH}$. Subsequently, Zhang et $\mathrm{al}^{218}$ designed folic acid and $\mathrm{SO}_{3} \mathrm{H}$ groups conjugated with GO and loaded with DOX and camptothecin via $\pi-\pi$ stacking in a controlled manner. GO with a folic acid ligand exhibited specific targeting and enhanced cytotoxicity to $\mathrm{MCF}-7$ cells. Hong et $\mathrm{a}^{216}$ fabricated protein-loaded polyelectrolyte multilayer films and demonstrated that proteins can be released in sequence with multiday gaps between the release of each species by incorporating GO layers between protein-loaded layers and found low cytotoxic effect in hematopoietic stem cells. Magnetite NP-decorated reduced graphene oxide $(\mathrm{Fe}(3) \mathrm{O}(4) / \mathrm{rGO})$ showed successful internalization of $\mathrm{Fe}(3) \mathrm{O}(4) / \mathrm{rGO}$ into the cytoplasm compared to
rGO and significantly higher cytotoxicity in $\mathrm{MCF}-7$ breast cancer cells. ${ }^{219}$ Functionalization of GO with the active targeting ligand TRC105 increased therapeutic efficacy in angiogenesis. ${ }^{216}$ A multiple supramolecular assembly was fabricated with a folic acid-modified beta-cyclodextrin, adamantanyl porphyrin, and GO through non-covalent interactions. Owing to the cooperative contribution of these three units, the DOX showed better drug activity and much lower toxicity. ${ }^{220}$ In vitro studies of GO-loaded adriamycin (ADR) showed that GO significantly enhanced the accumulation and toxicity, and reversed ADR resistance compared to free ADR. ${ }^{221}$ A novel multicomponent graphene nanostructured system containing $\mathrm{Fe}(3) \mathrm{O}(4)(\mathrm{Fe}) \mathrm{NPs}$, PAMAM-G4-NH(2) (G4) dendrimers, and Cy5 on a GO substrate exhibited high dispersion in an aqueous medium, and was magnetically responsive and fluorescent. This system was nontoxic and enhanced the successful uptake and distribution of the GO-G4-Fe-Cy5 nanosystem by MCF-7 breast cancer cells compared to free $\mathrm{Cy} 5 .^{222}$ Shen et $\mathrm{al}^{32}$ demonstrated the utility of PEGylated GO for efficient delivery of proteins into cells. In this approach, polyethylene glycol-treated graphene oxide (GO-PEG) delivered proteins to the cytoplasm efficiently, protecting them from enzymatic hydrolysis. Fan et $\mathrm{al}^{223}$ developed a water-soluble novel nanocarrier of magnetic $\mathrm{Fe}(3) \mathrm{O}(4)$-graphene nanocomposites, which showed excellent dispersibility and stability in aqueous solution and also exhibited superparamagnetic properties. Miao et al ${ }^{224}$ fabricated cholesteryl hyaluronic acid-reduced graphene oxide (CHA-rGO) nanosheets that showed increased colloidal stability, safety, and drug-loading capacity in mice. The in vivo antitumor efficacy of DOX delivered by CHA-rGO was significantly increased compared with free DOX or DOX-loaded rGO. Functionalization of GO with VEGF as the targeting ligand significantly enhanced in vivo tumor vasculature-targeting efficacy and showed excellent in vivo stability. 225

Recently, graphene-based nanocomposites have been used for multimodal bio-imaging and imaging-guided cancer therapy. Graphene and its nanocomposites have emerged as new biomaterials for the development of a new generation of biosensors, nanocarriers, and probes for cell and biological imaging. ${ }^{32}$ For example, graphene has been proposed as an excellent substrate for biomolecular imaging for introducing nanopores used for DNA sequencing, ${ }^{226,227}$ and as a component in electrodes for neural stimulation. ${ }^{228}$ Graphene and graphene derivatives have been used to detect various biological molecules such as dopamine, ${ }^{229}$ amino acids, ${ }^{230}$ thrombin, ${ }^{231}$ ATP, ${ }^{232}$ and oligonucleotides. ${ }^{233}$ Several specific features 
of graphene, including its efficient fluorescence-quenching ability, and its unique electronic properties, have enabled its use in developing biosensors. ${ }^{231,232}$ PEG-modified GO loaded with chemical drugs leverages the intrinsic fluorescence of GO in the NIR region, and gelatin-grafted rGO labeled with a fluorescent dye is used for cellular imaging and drug delivery. ${ }^{23,26}$ Inorganic quantum dots exhibit significantly enhanced fluorescent performance for bio-imaging. ${ }^{234-236}$ In addition, GQDs possess unique optical properties such as $\mathrm{pH}$-dependent and upconversion fluorescence behaviors, and GQDs are extensively used for cellular imaging in cells, organs, or tissues in this region. ${ }^{237,238}$ Recently, Chen et al ${ }^{239}$ reported the synthesis of composites of dextran-coated $\mathrm{Fe}_{3} \mathrm{O}_{4}$ NPs and $\mathrm{GO}\left(\mathrm{Fe}_{3} \mathrm{O}_{4}-\mathrm{GO}\right)$ as $\mathrm{T} 2$-weighted contrast agents for efficient cellular magnetic resonance imaging (MRI). Squaraine dyes were loaded inside mesoporous silica NPs, and the NP surfaces were then wrapped with ultrathin GO sheets; the resulted product exhibited remarkable stability and efficiently protected the loaded dye from nucleophilic attack. This hybrid material is non-cytotoxic and is used for fluorescence imaging. ${ }^{240}$ Nanographene has been used in noninvasive positron emission tomography imaging for in vivo tumor targeting and quantitative evaluation of drug pharmacokinetics and tumor-targeting efficacy. ${ }^{216}$ Grafted with PEG molecules, GO NPs exhibited high chemical stability at various $\mathrm{pH}$ values. Under in vitro conditions, the distribution of GO-PEG NPs in cellular/subcellular components was evaluated using two-photon luminescence imaging. For in vivo imaging, GOPEG NPs were intravenously injected into mice via the tail vein, and their flow, distribution, and clearance from blood vessels were observed by utilizing a deep-penetrating twophoton imaging technique. ${ }^{241}$ Gollavelli and Ling ${ }^{242}$ linked a polyacrylic acid bridge with fluorescein $O$-methacrylate to yield multifunctional graphene (MFG) with water dispersibility via a green synthetic approach. An in vitro study of cytotoxicity in HeLa cells revealed that MFG is a biocompatible imaging probe with an $\mathrm{IC}_{50}$ value of $\sim 100 \mu \mathrm{g} / \mathrm{mL}$; no significant abnormalities or effects on the survival rate were observed after microinjection of MFG. The rGO conjugate, (64)Cu-NOTA-rGO-TRC105, exhibited excellent stability in vitro and in vivo. In vivo, in vitro, and ex vivo studies confirmed the specificity of (64)Cu-NOTA-rGO-TRC105 for tumor vascular CD105. ${ }^{243}$ Lalwani et $\mathrm{al}^{244}$ reported that oxidized single- and multi-walled GO nanoribbons exhibit approximately five- to tenfold signal enhancement for photoacoustic tomography in comparison to blood at the wavelength of $755 \mathrm{~nm}$, and $\sim 10 \%-28 \%$ signal enhancement for thermoacoustic tomography (TAT) in comparison to deionized water at $3 \mathrm{GHz}$. Oxidized graphene nanoribbons show promise as multimodal photoacoustic tomography and TAT contrast agents, and oxidized graphene NPs are suitable contrast agents for TAT. GO has been coupled with anti-Her2 antibody, which is used for the treatment of breast cancer, and radiolabeled with [In111]-benzyl-diethylene-triaminepenta-acetic acid via $\pi-\pi$ stacking for targeted and functional imaging. ${ }^{245}$ A magnetic graphene complex was used to identify metastatic pancreatic cells in the lymph nodes and also used for direct guided PTT against cancer cells. ${ }^{246}$ Gollavelli and Ling ${ }^{247}$ used magnetic graphene as a potential theranostic nanocarrier for MRI and fluorescence dual-modality imaging and for PDT and PTT. Recently, Zhang et $\mathrm{al}^{248}$ developed a new colorimetric assay for the direct detection of cancer cells using graphene as a signal transducer. Interestingly, graphene was used as a biosensor for molecular marker analysis in cancer diagnosis in the field of in vitro detection tool development. Liu et $\mathrm{al}^{249}$ developed a method for reliable quantification of miRNAs in medical research and early clinical diagnostics, which is stable, sensitive, and specific for miRNA detection. The extraordinary fluorescence quenching of GO provided a high signal-to-noise ratio. Due to protection of the target miRNA by GO, cooperative amplification, low background fluorescence, and sensitive and accurate detection of miRNAs have been achieved.

BaGdF5 NPs attached to GO showed low cytotoxicity, positive magnetic resonance contrast effect, and better X-ray attenuation properties than iohexol. ${ }^{250}$ Yan et al $^{251}$ designed and prepared a novel photo-theranostic agent for enhanced optical imaging using sinoporphyrin sodium-loaded GOPEG, with improved fluorescence properties. Figure 4 shows the possible application of graphene and graphene-related materials in bio-imaging of live animals.

Tissue engineering uses biological materials for maintenance and improvement of the functions of tissues or organs. Graphene and its derivatives are having a crucial role in tissue engineering due to their unique physicochemical properties. In order to spread, proliferate, and perform their functions, cells or tissues need a good substrate, and graphene and GO can play this vital role in tissue engineering. Due to their mechanical properties, they are suitable for the structural reinforcement of biocompatible films, hydrogels, and other scaffolding materials frequently used in tissue engineering. 31

MSCs are multipotent progenitor cells derived from adult bone marrow, and have shown promising applications in tissue repair and cell therapies. ${ }^{252,253}$ The differentiation of MSCs is controlled by several factors including 


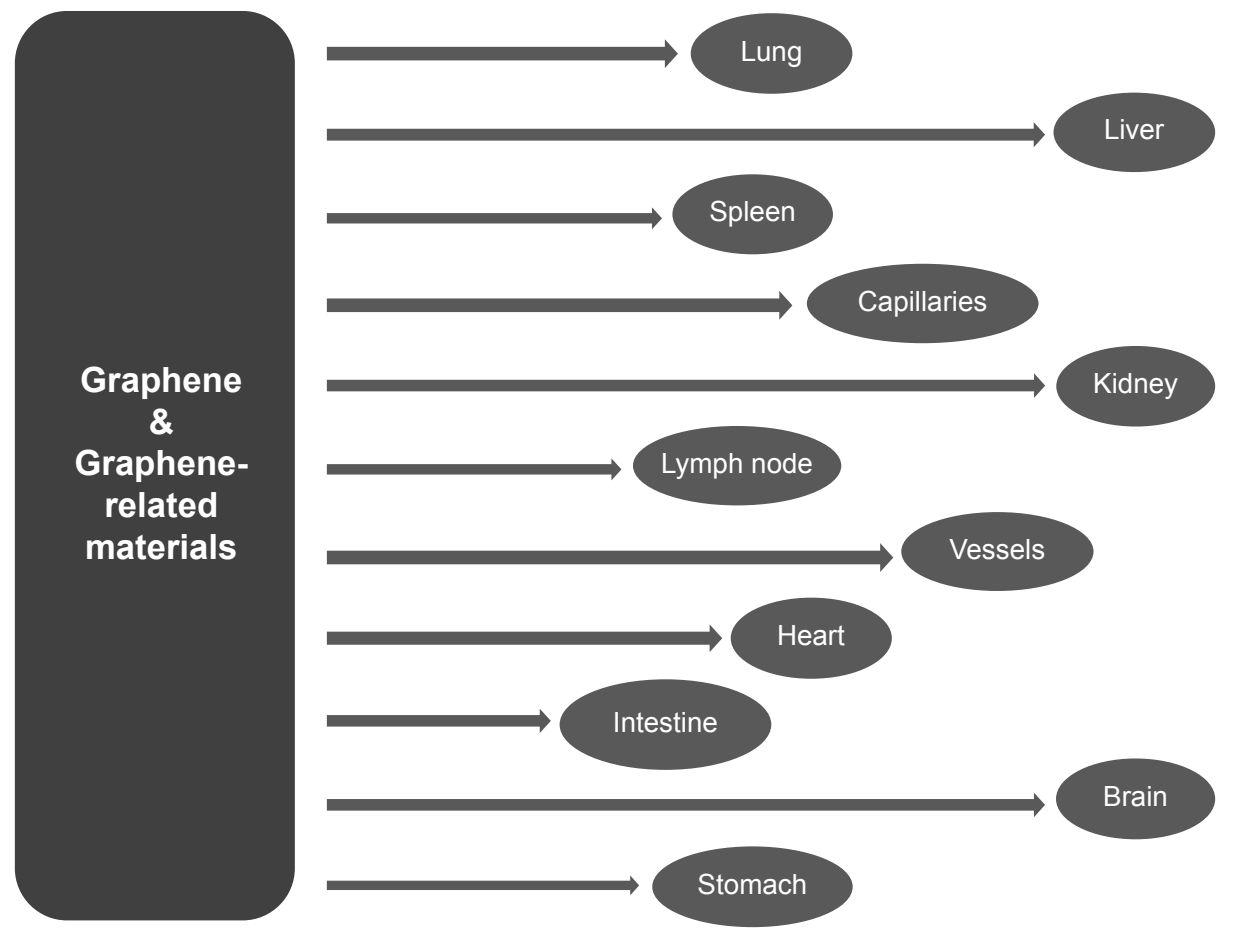

Figure 4 Graphene and graphene-related materials can be used as probes for whole-body functional in vivo bio-imaging of live animals.

the microenvironment via material mechanics, ${ }^{254}$ substrate topography, ${ }^{255}$ soluble growth factors, ${ }^{256}$ and osteogenic inducers, such as dexamethasone and beta-glycerolphosphate. ${ }^{191}$ Graphene-reinforced chitosan films showed enhanced mechanical and biocompatibility properties in murine fibrosarcoma L929 cell culture. ${ }^{189}$ GO-reinforced chitosan scaffolds significantly improved cellular adhesion, proliferation, differentiation, and calcium and phosphate deposition of MC3T3-E1 cells, a mouse preosteoblast cell line. ${ }^{197}$ Lee et al ${ }^{191}$ explored the possibility of using graphene and GO as substrates for MSC adhesion, proliferation, and differentiation, and found that graphene and GO accelerated stem cell growth and differentiation through molecular interactions. Combination of GO and polyvinyl alcoholbased hydrogels significantly enhanced the tensile strength and compressive strength of a composite hydrogel without affecting its cytocompatibility. ${ }^{178}$ Nayak et al ${ }^{199}$ observed controlled and accelerated osteogenic differentiation of MSCs in the presence of BMP-2. The differentiation of human neural stem cells plays an important role in brain repair and neural regeneration. ${ }^{257}$ For example, graphene substrate significantly enhanced cell adhesion, neurite outgrowth, and differentiation of human neural stem cells more toward neurons than glial cells. ${ }^{258} \mathrm{Li}$ et al ${ }^{203}$ compared the efficiency of tissue culture polystyrene substrates with and without graphene, and they found that graphene films with excellent biocompatibility significantly promoted neurite sprouting and outgrowth of mouse hippocampal neurons, especially during the early developmental phase. Lu et $\mathrm{a}^{259}$ examined chitosan-polyvinyl alcohol nanofibrous scaffolds with and without graphene for wound healing. They found that graphene-containing nanocomposites show fast wound healing, spontaneous differentiation, iPSC proliferation, and endodermal differentiation. ${ }^{193} \mathrm{Ku}$ and Park ${ }^{260}$ studied the behavior of mouse myoblast $\mathrm{C} 2 \mathrm{C} 12$ cells, including adhesion, proliferation, and differentiation, on unmodified, GO-modified, and rGO-modified glass substrates. They found that GO was able to stimulate expression of myogenic protein, enhance myotube formation, and induce expression of differentiation-specific genes. ${ }^{244}$ Two-dimensional-reinforced polypropylene fumarate nanocomposites such as GO nanoplatelets and molybdenum disulfide nanoplatelets showed better performance as reinforcing agents than one-dimensional nanostructures or single- or multi-walled carbon nanotubes. Calcium adsorption, ALP activity, and growth rate of MC3T3-E1 cells were increased using both GO- and rGO-coated scaffolds compared to noncoated scaffolds. ${ }^{261}$ An artificial matrix (Fn-Tigra), consisting of GO and fibronectin on a pure titanium substrate, enhanced the biocompatibility, cellular behavior, and osteogenic potential of preosteoblasts compared to Ti and Ti-GO (Tigra) substrates. In addition, cell proliferation, viability, and focal 
adhesion molecule (vinculin) expression were significantly higher on Fn-Tigra and Tigra than that of cells grown on $\mathrm{Ti}^{262}$ Lee et $\mathrm{al}^{263}$ observed that bone marrow-derived MSCs cultured in a solution containing graphene flakes showed increased chondrogenic differentiation. GO sheets composed of GO nanoplatelets and electrospun fibrous meshes of GO-poly-caprolactone composite exhibited significant myoblast differentiation and myotube formation. ${ }^{264}$ Fabrication of GO-doped poly(lactic-co-glycolic acid) nanofiber scaffolds accelerated the adhesion and proliferation of human MSCs versus pure poly(lactic-co-glycolic acid) nanofibers and induced osteogenic differentiation. ${ }^{265}$ Primary mouse embryonic fibroblast cells showed significant attachment and survival with amine-reduced GO (Figure 5).

\section{Conclusion and future perspectives}

The numbers of studies of graphene and graphene derivatives have increased tremendously in the last 5 years. A large number of studies have been dedicated to developing chemical routes for synthesis and applications of graphene in biotechnology, biomedical engineering, nanomedicine, cancer therapy, tissue engineering, drug delivery, bioimaging, and biomolecular sensing. However, the number of studies focused on synthesis of graphene using biological molecules is limited. The functional properties of graphene and graphene derivatives depend on size, surface charge, layer number, lateral dimensions, and surface chemistry, and all of these parameters can affect biological systems. The interaction between graphene and biological systems makes graphene an attractive molecule both in academia and industry. In this review, we summarize environmentally friendly approaches for synthesis of graphene using various biological systems, including bacteria, plant extracts, and small molecules. A number of studies have been published on the potential toxicity of graphene, but many discrepancies between the results remain. These varying results are due to the many factors involved, and the intrinsic physicochemical properties (such as surface functional groups, charges, coatings, sizes, and structural defects) of graphene, as well as differences in size dimensions, functionalization, and purification can all affect its in vitro and in vivo behavior, as well as its toxicity to biological systems. The properties of graphene are also dependent on the raw materials used for production. Therefore, understanding the toxicity of graphene in biological systems both in vitro and in vivo is of utmost importance for further development of graphene-based nanomedicine, as well as for providing safety guidelines for all researchers working with this new type of nanomaterial. Another important issue for biomedical applications of graphene is its short- and long-term toxicity. To date, no systematic studies of this subject have been published, and the detailed mechanisms of the cellular toxicity of graphene, in vitro and in vivo, remain obscure. Another important concern in using graphene in biomedical applications is its biocompatibility. Based on the available literature, we have summarized the possible important aspects of synthesis, toxicity, biocompatibility, and biomedical applications with special reference to cancer therapy, drug delivery, bio-imaging, and tissue engineering. Further, more studies of systematic toxicity versus biocompatibility, particularly in animal models, are required to understand the biological effects and the safety of graphene, before graphene-based nanotherapy can be applied for human welfare. It is necessary to carefully address its solubility, biodegradability, and retention in aqueous solutions. Future studies should focus on functionalization of graphene, excretion of graphene in
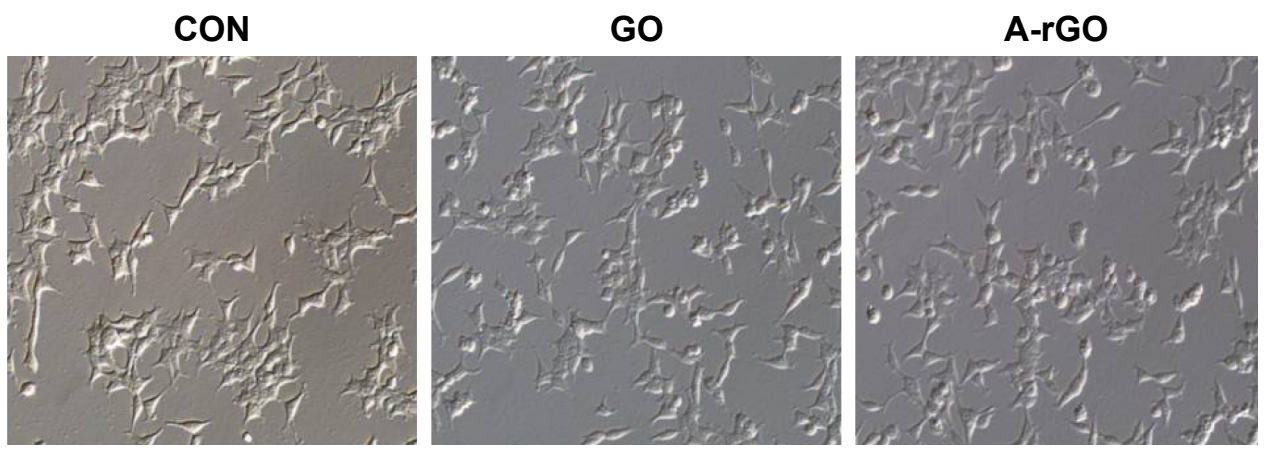

Figure 5 Effect of GO and A-rGO on the survival of MEFs.

Notes: Micrographs showing PMEFC attachment and growth on a non-coated dish (control), a dish coated with GO, and a dish coated with A-rGO. All coated dishes and a control uncoated dish were placed in the same culture conditions and allowed to incubate for 24 hours at $37^{\circ} \mathrm{C}$. GO and A-rGO were good substrates for cell growth.

Abbreviations: CON, control; GO, graphene oxide; rGO, reduced graphene oxide; A-rGO, protein-reduced GO; MEFs, primary mouse embryonic fibroblast cells. 
animals, and the pharmacokinetics and behavior of graphene in living systems using in vivo animal models. However, graphene and graphene derivatives have made great advancements in the fields of drug delivery and nanomedicine, which may open up new avenues for exciting opportunities to improve human welfare.

\section{Acknowledgments}

This paper was supported by the KU-Research Professor Program of Konkuk University.

The authors would like to thank the great many people who have contributed to the field of graphene research. We owe our gratitude to all those researchers who have made this review possible. The authors would like to mention that they have cited as many references as permitted, and apologize to the authors of those publications that have not been cited due to limitation of references.

\section{Disclosure}

The authors report no conflicts of interest in this work.

\section{References}

1. Novoselov KS, Geim AK, Morozov SV, et al. Electric field effect in atomically thin carbon films. Science. 2004;306(5696):666-669.

2. Novoselov KS, Fal'ko VI, Colombo L, Gellert PR, Schwab MG, Kim K. A roadmap for graphene. Nature. 2012;490(7419):192-200.

3. Edwards RS, Coleman KS. Graphene synthesis: relationship to applications. Nanoscale. 2013;5(1):38-51.

4. Suk JW, Lee WH, Lee J, et al. Enhancement of the electrical properties of graphene grown by chemical vapor deposition via controlling the effects of polymer residue. Nano Lett. 2013;13(4):1462-1467.

5. Nair RR, Blake $P$, Grigorenko AN, et al. Fine structure constant defines visual transparency of graphene. Science. 2008;320(5881):1308.

6. Liu F, Ming PM, Li J. Ab initio calculation of ideal strength and phonon instability of graphene under tension. Phys Rev B. 2007;76(6):064120.

7. Lee C, Wei XD, Kysar JW, Hone J. Measurement of the elastic properties and intrinsic strength of monolayer graphene. Science. 2008; 321(5887):385-388.

8. Balandin AA. Thermal properties of graphene and nanostructured carbon materials. Nat Mater. 2011;10(8):569-581.

9. Loh KP, Bao QL, Ang PK, Yang JX. The chemistry of graphene. J Mater Chem. 2010;20(12):2277-2289.

10. Bunch JS, Verbridge SS, Alden JS, et al. Impermeable atomic membranes from graphene sheets. Nano Lett. 2008;8(8):2458-2462.

11. Wu SX, He QY, Tan CL, Wang YD, Zhang H. Graphene-based electrochemical sensors. Small. 2013;9(8):1160-1172.

12. Xu CH, Xu BH, Gu Y, Xiong ZG, Sun J, Zhao XS. Graphene-based electrodes for electrochemical energy storage. Energy Environ Sci. 2013;6(5):1388-1414.

13. Chen Y, Prasad KP, Wang XW, et al. Enzymeless multi-sugar fuel cells with high power output based on 3D graphene-Co3O4 hybrid electrodes. Phys Chem Chem Phys. 2013;15(23):9170-9176.

14. Lee GH, Cooper RC, An SJ, et al. High-strength chemical-vapor deposited graphene and grain boundaries. Science. 2013;340(6136): 1073-1076.

15. Feng LZ, Liu ZA. Graphene in biomedicine: opportunities and challenges. Nanomedicine (Lond). 2011;6(2):317-324.
16. Goncalves G, Vila M, Portoles MT, Vallet-Regi M, Gracio J, Marques PAAP. Nano-graphene oxide: a potential multifunctional platform for cancer therapy. Adv Healthc Mater. 2013;2(8):1072-1090.

17. Wang Y, Huang RQ, Liang GH, et al. MRI-visualized, dual-targeting, combined tumor therapy using magnetic graphene-based mesoporous silica. Small. 2014;10(1):109-116.

18. Castillo JJ, Svendsen WE, Rozlosnik N, Escobar P, Martineza F, Castillo-Leon J. Detection of cancer cells using a peptide nanotube-folic acid modified graphene electrode. Analyst. 2013;138(4):1026-1031.

19. Chen JY, Chen SM, Weng WH, Li Y, Yeh SD. Simultaneous detection of DNA bases on electrodes chemically modified with graphene-new fuchsin. Int J Electrochem Sci. 2013;8(3):3963-3973.

20. Hu CF, Liu YL, Qin JL, et al. Fabrication of reduced graphene oxide and silver nanoparticle hybrids for Raman detection of absorbed folic acid: a potential cancer diagnostic probe. ACS Appl Mater Interfaces. 2013;5(11):4760-4768.

21. Kwon OS, Lee SH, Park SJ, et al. Large-scale graphene micropattern nano-biohybrids: high-performance transducers for FET-type flexible fluidic HIV immunoassays. Adv Mater. 2013;25(30):4177-4185.

22. Wang XD, Chen LJ, Su XR, Ai SY. Electrochemical immunosensor with graphene quantum dots and apoferritin-encapsulated $\mathrm{Cu}$ nanoparticles double-assisted signal amplification for detection of avian leukosis virus subgroup J. Biosens Bioelectron. 2013;47:171-177.

23. Liu KP, Zhang JJ, Cheng FF, Zheng TT, Wang CM, Zhu JJ. Green and facile synthesis of highly biocompatible graphene nanosheets and its application for cellular imaging and drug delivery. J Mater Chem. 2011;21(32):12034-12040.

24. Pan YZ, Sahoo NG, Li L. The application of graphene oxide in drug delivery. Expert Opin Drug Deliv. 2012;9(11):1365-1376.

25. Shen H, Zhang LM, Liu M, Zhang ZJ. Biomedical applications of graphene. Theranostics. 2012;2(3):283-294.

26. Sun XM, Liu Z, Welsher K, et al. Nano-graphene oxide for cellular imaging and drug delivery. Nano Res. 2008;1(3):203-212.

27. Yang K, Zhang SA, Zhang GX, Sun XM, Lee ST, Liu ZA. Graphene in mice: ultrahigh in vivo tumor uptake and efficient photothermal therapy. Nano Lett. 2010;10(9):3318-3323.

28. Akhavan O, Ghaderi E. Toxicity of graphene and graphene oxide nanowalls against bacteria. ACS Nano. 2010;4(10):5731-5736.

29. Hu WB, Peng C, Luo WJ, et al. Graphene-based antibacterial paper. ACS Nano. 2010;4(7):4317-4323.

30. Liu SB, Zeng TH, Hofmann M, et al. Antibacterial activity of graphite, graphite oxide, graphene oxide, and reduced graphene oxide: membrane and oxidative stress. ACS Nano. 2011;5(9):6971-6980.

31. Sanchez VC, Jachak A, Hurt RH, Kane AB. Biological interactions of graphene-family nanomaterials: an interdisciplinary review. Chem Res Toxicol. 2012;25(1):15-34.

32. Shen AJ, Li DL, Cai XJ, et al. Multifunctional nanocomposite based on graphene oxide for in vitro hepatocarcinoma diagnosis and treatment. J Biomed Mater Res A. 2012;100A(9):2499-2506.

33. Yang K, Li YJ, Tan XF, Peng R, Liu Z. Behavior and toxicity of graphene and its functionalized derivatives in biological systems. Small. 2013;9(9-10):1492-1503.

34. Chung C, Kim YK, Shin D, Ryoo SR, Hong BH, Min DH. Biomedical applications of graphene and graphene oxide. Acc Chem Res. 2013;46(10):2211-2224.

35. Liu Y, Zhao YL, Sun BY, Chen CY. Understanding the toxicity of carbon nanotubes. Acc Chem Res. 2013;46(3):702-713.

36. Mao XW, Li HB. Chiral imaging in living cells with functionalized graphene oxide. J Mater Chem B. 2013;1(34):4267-4272.

37. Feng LZ, Yang XZ, Shi XZ, et al. Polyethylene glycol and polyethylenimine dual-functionalized nano-graphene oxide for photothermally enhanced gene delivery. Small. 2013;9(11):1989-1997.

38. Goenka S, Sant V, Sant S. Graphene-based nanomaterials for drug delivery and tissue engineering. J Control Release. 2014;173:75-88.

39. Guo XQ, Mei N. Assessment of the toxic potential of graphene family nanomaterials. J Food Drug Anal. 2014;22(1):105-115. 
40. Chen YM, Ren CX, Ouyang SH, Hu XG, Zhou QX. Mitigation in multiple effects of graphene oxide toxicity in zebrafish embryogenesis driven by humic acid. Environ Sci Technol. 2015;49(16): 10147-10154.

41. Orecchioni M, Cabizza R, Bianco A, Delogu LG. Graphene as cancer theranostic tool: progress and future challenges. Theranostics. 2015;5(7):710-723.

42. Geim AK, Novoselov KS. The rise of graphene. Nat Mater. 2007;6(3): 183-191.

43. Lui CH, Li ZQ, Chen ZY, Klimov PV, Brus LE, Heinz TF. Imaging stacking order in few-layer graphene. Nano Lett. 2011;11(1): 164-169.

44. Mak KF, Shan J, Heinz TF. Electronic structure of few-layer graphene: experimental demonstration of strong dependence on stacking sequence. Phys Rev Lett. 2010;104(17):176404.

45. Hunt B, Sanchez-Yamagishi JD, Young AF, et al. Massive Dirac fermions and Hofstadter butterfly in a van der Waals heterostructure. Science. 2013;340(6139):1427-1430.

46. Kharche N, Zhou Y, O'Brien KP, Kar S, Nayak SK. Effect of layer stacking on the electronic structure of graphene nanoribbons. ACS Nano. 2011;5(8):6096-6101.

47. Ma R, Wang L. Thermoelectric and thermal transport properties in ABA-stacked trilayer graphene. Eur Phys J B. 2012;85(8):263.

48. Enoki T, Fujii S, Takai K. Zigzag and armchair edges in graphene. Carbon. 2012;50(9):3141-3145.

49. Goto H, Uesugi E, Eguchi R, Fujiwara A, Kubozono Y. Edge-dependent transport properties in graphene. Nano Lett. 2013;13(3):1126-1130.

50. Zhang H, Duan Z, Zhang XN, Liu C, Zhang JF, Zhao JJ. Strength and fracture behavior of graphene grain boundaries: effects of temperature, inflection, and symmetry from molecular dynamics. Phys Chem Chem Phys. 2013;15(28):11794-11799.

51. Lee JU, Yoon D, Cheong H. Estimation of Young's modulus of graphene by Raman spectroscopy. Nano Lett. 2012;12(9):4444-4448.

52. Jiang J-W, Wang J-S, Li B. Young's modulus of graphene: a molecular dynamics study. Phys Rev B. 2009;80(11):113405.

53. Bolotin KI, Sikes KJ, Jiang Z, et al. Ultrahigh electron mobility in suspended graphene. Solid State Commun. 2008;146(9-10):351-355.

54. Du X, Skachko I, Barker A, Andrei EY. Approaching ballistic transport in suspended graphene. Nat Nano. 2008;3(8):491-495.

55. Zhang JW, He XD, Yang L, et al. Effect of tensile strain on thermal conductivity in monolayer graphene nanoribbons: a molecular dynamics study. Sensors (Basel). 2013;13(7):9388-9395.

56. Zhang L, Zhang F, Yang X, et al. Porous 3D graphene-based bulk materials with exceptional high surface area and excellent conductivity for supercapacitors. Sci Rep. 2013;3:1408.

57. Li ZF, Zhang HY, Liu Q, Sun LL, Stanciu L, Xie J. Fabrication of high-surface-area graphene/polyaniline nanocomposites and their application in supercapacitors. ACS Appl Mater Interfaces. 2013; 5(7):2685-2691.

58. Ning GQ, Fan ZJ, Wang G, Gao JS, Qian WZ, Wei F. Gram-scale synthesis of nanomesh graphene with high surface area and its application in supercapacitor electrodes. Chem Commun (Camb). 2011; 47(21):5976-5978.

59. Wang MX, Liu Q, Sun HF, et al. Preparation of high-surface-area carbon nanoparticle/graphene composites. Carbon. 2012;50(10): 3845-3853.

60. Worsley MA, Olson TY, Lee JRI, et al. High surface area, sp2-crosslinked three-dimensional graphene monoliths. J Phys Chem Lett. 2011; 2(8):921-925.

61. Zhang YB, Tan YW, Stormer HL, Kim P. Experimental observation of the quantum Hall effect and Berry's phase in graphene. Nature. 2005; 438(7065):201-204.

62. Chaoying W, Biqiong C. Poly(ع-caprolactone)/graphene oxide biocomposites: mechanical properties and bioactivity. Biomed Mater. 2011; 6(5):055010.

63. Sahni D, Jea A, Mata JA, et al. Biocompatibility of pristine graphene for neuronal interface. J Neurosurg Pediatr. 2013;11(5):575-583.
64. Zhu YW, Murali S, Cai WW, et al. Graphene and graphene oxide: synthesis, properties, and applications. Adv Mater. 2010;22(35): 3906-3924.

65. Wei DC, Liu YQ. Controllable synthesis of graphene and its applications. Adv Mater. 2010;22(30):3225-3241.

66. Park S, Ruoff RS. Chemical methods for the production of graphenes. Nat Nanotechnol. 2009;4(4):217-224.

67. Mao M, Wang MM, Hu JY, Lei G, Chen SZ, Liu HT. Simultaneous electrochemical synthesis of few-layer graphene flakes on both electrodes in protic ionic liquids. Chem Commun (Camb). 2013;49(46): 5301-5303.

68. Hass J, de Heer WA, Conrad EH. The growth and morphology of epitaxial multilayer graphene. J Phys Condens Mater. 2008;20(32):323202.

69. Allen MJ, Wang MS, Jannuzzi SAV, Yang Y, Wang KL, Kaner RB. Chemically induced folding of single and bilayer graphene. Chem Commun (Camb). 2009;41:6285-6287.

70. Van Noorden R. Production: beyond sticky tape. Nature. 2012;483(7389): S32-S33

71. Jayasena B, Reddy CD, Subbiah S. Separation, folding and shearing of graphene layers during wedge-based mechanical exfoliation. Nanotechnology. 2013;24(20):205301.

72. Parvez K, Li RJ, Puniredd SR, et al. Electrochemically exfoliated graphene as solution-processable, highly conductive electrodes for organic electronics. ACS Nano. 2013;7(4):3598-3606.

73. Liu JL, Poh CK, Zhan D, et al. Improved synthesis of graphene flakes from the multiple electrochemical exfoliation of graphite rod. Nano Energy. 2013;2(3):377-386.

74. Wang GX, Wang B, Park J, Wang Y, Sun B, Yao J. Highly efficient and large-scale synthesis of graphene by electrolytic exfoliation. Carbon. 2009;47(14):3242-3246.

75. Su CY, Lu AY, Xu YP, Chen FR, Khlobystov AN, Li LJ. High-quality thin graphene films from fast electrochemical exfoliation. ACS Nano. 2011;5(3):2332-2339.

76. Brownson DAC, Metters JP, Kampouris DK, Banks CE. Graphene electrochemistry: surfactants inherent to graphene can dramatically effect electrochemical processes. Electroanalysis. 2011;23(4): 894-899.

77. Poh HL, Sanek F, Ambrosi A, Zhao GJ, Sofer Z, Pumera M. Graphenes prepared by Staudenmaier, Hofmann and Hummers methods with consequent thermal exfoliation exhibit very different electrochemical properties. Nanoscale. 2012;4(11):3515-3522.

78. Zhu YW, Stoller MD, Cai WW, et al. Exfoliation of graphite oxide in propylene carbonate and thermal reduction of the resulting graphene oxide platelets. ACS Nano. 2010;4(2):1227-1233.

79. Zhu YW, Murali S, Stoller MD, Velamakanni A, Piner RD, Ruoff RS. Microwave assisted exfoliation and reduction of graphite oxide for ultracapacitors. Carbon. 2010;48(7):2118-2122.

80. Sutter PW, Flege JI, Sutter EA. Epitaxial graphene on ruthenium. Nat Mater. 2008;7(5):406-411.

81. Kim YS, Kumar K, Fisher FT, Yang EH. Out-of-plane growth of CNTs on graphene for supercapacitor applications. Nanotechnology. 2012;23(1):015301.

82. Kim KS, Zhao Y, Jang H, et al. Large-scale pattern growth of graphene films for stretchable transparent electrodes. Nature. 2009;457(7230): 706-710.

83. Kosynkin DV, Higginbotham AL, Sinitskii A, et al. Longitudinal unzipping of carbon nanotubes to form graphene nanoribbons. Nature. 2009;458(7240):U872-U875.

84. Schniepp HC, Li JL, McAllister MJ, et al. Functionalized single graphene sheets derived from splitting graphite oxide. $J$ Phys Chem $B$. 2006;110(17):8535-8539.

85. Smith RJ, Lotya M, Coleman JN. The importance of repulsive potential barriers for the dispersion of graphene using surfactants. New $J$ Phys. 2010;12:125008.

86. Hernandez Y, Nicolosi V, Lotya M, et al. High-yield production of graphene by liquid-phase exfoliation of graphite. Nat Nanotechnol. 2008; 3(9):563-568. 
87. Coleman JN. Liquid-phase exfoliation of nanotubes and graphene. Adv Funct Mater. 2009;19(23):3680-3695.

88. Zeng ZY, Sun T, Zhu JX, et al. An effective method for the fabrication of few-layer-thick inorganic nanosheets. Angew Chem Int Ed Engl. 2012;51(36):9052-9056.

89. Zeng ZY, Yin ZY, Huang X, et al. Single-layer semiconducting nanosheets: high-yield preparation and device fabrication. Angew Chem Int Ed Engl. 2011;50(47):11093-11097.

90. Matte HSSR, Gomathi A, Manna AK, et al. MoS2 and WS2 analogues of graphene. Angew Chem Int Ed Engl. 2010;49(24):4059-4062.

91. Stankovich S, Piner RD, Chen XQ, Wu NQ, Nguyen ST, Ruoff RS Stable aqueous dispersions of graphitic nanoplatelets via the reduction of exfoliated graphite oxide in the presence of poly(sodium 4-styrenesulfonate). J Mater Chem. 2006;16(2):155-158.

92. Akhavan O, Ghaderi E. Photocatalytic reduction of graphene oxide nanosheets on $\mathrm{TiO} 2$ thin film for photoinactivation of bacteria in solar light irradiation. J Phys Chem C. 2009;113(47):20214-20220.

93. Akhavan O, Abdolahad M, Esfandiar A, Mohatashamifar M. Photodegradation of graphene oxide sheets by $\mathrm{TiO} 2$ nanoparticles after a photocatalytic reduction. J Phys Chem C. 2010;114(30):12955-12959.

94. Kim J, Ishihara M, Koga Y, Tsugawa K, Hasegawa M, Iijima S. Low-temperature synthesis of large-area graphene-based transparent conductive films using surface wave plasma chemical vapor deposition. Appl Phys Lett. 2011;98(9):091502.

95. Hummers WS, Offeman RE. Preparation of graphitic oxide. $J$ Am Chem Soc. 1958;80(6):1339.

96. Eigler S, Grimm S, Enzelberger-Heim M, Muller P, Hirsch A. Graphene oxide: efficiency of reducing agents. Chem Commun (Camb). 2013;49(67):7391-7393.

97. Pei SF, Cheng HM. The reduction of graphene oxide. Carbon. 2012; 50(9):3210-3228.

98. Gao XF, Jang J, Nagase S. Hydrazine and thermal reduction of graphene oxide: reaction mechanisms, product structures, and reaction design. J Phys Chem C. 2010;114(2):832-842.

99. Park S, An J, Potts JR, Velamakanni A, Murali S, Ruoff RS. Hydrazine-reduction of graphite- and graphene oxide. Carbon. 2011;49(9): 3019-3023.

100. Paul H, Mohanta D. Hydrazine reduced exfoliated graphene/graphene oxide layers and magnetoconductance measurements of Ge-supported graphene layers. Appl Phys A Mater. 2011;103(2):395-402.

101. Wang RH, Wang Y, Xu CH, Sun J, Gao L. Facile one-step hydrazineassisted solvothermal synthesis of nitrogen-doped reduced graphene oxide: reduction effect and mechanisms. RSC Adv. 2013;3(4): 1194-1200.

102. Chua CK, Pumera M. Reduction of graphene oxide with substituted borohydrides. J Mater Chem A. 2013;1(5):1892-1898.

103. Feng HB, Cheng R, Zhao X, Duan XF, Li JH. A low-temperature method to produce highly reduced graphene oxide. Nat Commun. 2013;4:1539.

104. Shin HJ, Kim KK, Benayad A, et al. Efficient reduction of graphite oxide by sodium borohydride and its effect on electrical conductance. Adv Funct Mater. 2009;19(12):1987-1992.

105. Liu HT, Zhang L, Guo YL, et al. Reduction of graphene oxide to highly conductive graphene by Lawesson's reagent and its electrical applications. J Mater Chem C. 2013;1(18):3104-3109.

106. Chua CK, Ambrosi A, Pumera M. Graphene oxide reduction by standard industrial reducing agent: thiourea dioxide. J Mater Chem. 2012;22(22):11054-11061

107. Liu YZ, Li YF, Yang YG, Wen YF, Wang MZ. Reduction of graphene oxide by thiourea. J Nanosci Nanotechnol. 2011;11(11): 10082-10086.

108. Dreyer DR, Jia HP, Bielawski CW. Graphene oxide: a convenient carbocatalyst for facilitating oxidation and hydration reactions. Angew Chem Int Ed Engl. 2010;49(38):6813-6816.

109. Eda G, Chhowalla M. Chemically derived graphene oxide: towards large-area thin-film electronics and optoelectronics. Adv Mater. 2010; 22(22):2392-2415.
110. Stankovich S, Dikin DA, Piner RD, et al. Synthesis of graphenebased nanosheets via chemical reduction of exfoliated graphite oxide. Carbon. 2007:45(7):1558-1565.

111. Gurunathan S, Woong Han J, Kim E, Kwon DN, Park JK, Kim JH. Enhanced green fluorescent protein-mediated synthesis of biocompatible graphene. J Nanobiotechnol. 2014;12:41.

112. Akhavan O, Choobtashani M, Ghaderi E. Protein degradation and RNA efflux of viruses photocatalyzed by graphene-tungsten oxide composite under visible light irradiation. J Phys Chem C. 2012;116(17) 9653-9659.

113. Gurunathan S, Han JW, Kim ES, Park JH, Kim JH. Reduction of graphene oxide by resveratrol: a novel and simple biological method for the synthesis of an effective anticancer nanotherapeutic molecule. Int J Nanomed. 2015;10:2951-2969.

114. Khanra P, Kuila T, Kim NH, Bae SH, Yu DS, Lee JH. Simultaneous bio-functionalization and reduction of graphene oxide by baker's yeast. Chem Eng J. 2012;183:526-533.

115. Kim YK, Kim MH, Min DH. Biocompatible reduced graphene oxide prepared by using dextran as a multifunctional reducing agent. Chem Commun (Camb). 2011;47(11):3195-3197.

116. Gurunathan S, Han JW, Eppakayala V, Kim JH. Green synthesis of graphene and its cytotoxic effects in human breast cancer cells. Int $J$ Nanomed. 2013;8:1015-1027.

117. Gurunathan S, Han JW, Park JH, Eppakayala V, Kim JH. Ginkgo biloba: a natural reducing agent for the synthesis of cytocompatible graphene. Int J Nanomed. 2014;9:363-377.

118. Fan XB, Peng WC, Li Y, et al. Deoxygenation of exfoliated graphite oxide under alkaline conditions: a green route to graphene preparation. Adv Mater. 2008;20(23):4490-4493.

119. Min K, Han TH, Kim J, et al. A facile route to fabricate stable reduced graphene oxide dispersions in various media and their transparent conductive thin films. J Colloid Interface Sci. 2012;383:36-42.

120. Tang ZH, Wu XH, Guo BC, Zhang LQ, Jia DM. Preparation of butadiene-styrene-vinyl pyridine rubber-graphene oxide hybrids through co-coagulation process and in situ interface tailoring. J Mater Chem. 2012;22(15):7492-7501.

121. Gurunathan S, Han JW, Dayem AA, Eppakayala V, Kim JH. Oxidative stress-mediated antibacterial activity of graphene oxide and reduced graphene oxide in Pseudomonas aeruginosa. Int J Nanomed. 2012;7:5901-5914.

122. Gurunathan S, Han JW, Dayem AA, et al. Antibacterial activity of dithiothreitol reduced graphene oxide. J Ind Eng Chem. 2013; 19(4):1280-1288.

123. Gurunathan S, Han JW, Kim JH. Green chemistry approach for the synthesis of biocompatible graphene. Int J Nanomed. 2013;8: 2719-2732.

124. Salas EC, Sun ZZ, Luttge A, Tour JM. Reduction of graphene oxide via bacterial respiration. ACS Nano. 2010;4(8):4852-4856.

125. Wang GM, Qian F, Saltikov C, Jiao YQ, Li Y. Microbial reduction of graphene oxide by Shewanella. Nano Res. 2011;4(6):563-570.

126. Akhavan O, Ghaderi E. Escherichia coli bacteria reduce graphene oxide to bactericidal graphene in a self-limiting manner. Carbon. 2012;50(5):1853-1860.

127. Gurunathan S, Han JW, Eppakayala V, Kim JH. Microbial reduction of graphene oxide by Escherichia coli: a green chemistry approach. Colloids Surf B Biointerfaces. 2013;102:772-777.

128. Gurunathan S, Han JW, Eppakayala V, Jeyaraj M, Kim JH. An environmentally friendly approach to the reduction of graphene oxide by Escherichia fergusoni. J Nanosci Nanotechnol. 2013;13(3): 2091-2098

129. Gurunathan S, Han J, Park JH, Kim JH. An in vitro evaluation of graphene oxide reduced by Ganoderma spp. in human breast cancer cells (MDA-MB-231). Int J Nanomed. 2014;9:1783-1797.

130. Thakur S, Karak N. Green reduction of graphene oxide by aqueous phytoextracts. Carbon. 2012;50(14):5331-5339.

131. Iravani S. Green synthesis of metal nanoparticles using plants. Green Chem. 2011;13(10):2638-2650. 
132. Lee G, Kim BS. Biological reduction of graphene oxide using plant leaf extracts. Biotechnol Progr. 2014;30(2):463-469.

133. Al-Marri AH, Khan M, Khan M, et al. Pulicaria glutinosa extract: a toolbox to synthesize highly reduced graphene oxide-silver nanocomposites. Int J Mol Sci. 2015;16(1):1131-1142.

134. Khan M, Al-Marri AH, Khan M, et al. Green approach for the effective reduction of graphene oxide using Salvadora persica L. root (miswak) extract. Nanoscale Res Lett. 2015;10:281.

135. Fernandez-Merino MJ, Guardia L, Paredes JI, et al. Vitamin C is an ideal substitute for hydrazine in the reduction of graphene oxide suspensions. J Phys Chem C. 2010;114(14):6426-6432.

136. Akhavan O, Ghaderi E, Aghayee S, Fereydooni Y, Talebi A. The use of a glucose-reduced graphene oxide suspension for photothermal cancer therapy. J Mater Chem. 2012;22(27):13773-13781.

137. Zhu CZ, Guo SJ, Fang YX, Dong SJ. Reducing sugar: new functional molecules for the green synthesis of graphene nanosheets. ACS Nano. 2010;4(4):2429-2437.

138. Liu JB, Fu SH, Yuan B, Li YL, Deng ZX. Toward a universal "adhesive nanosheet" for the assembly of multiple nanoparticles based on a protein-induced reduction/decoration of graphene oxide. J Am Chem Soc. 2010;132(21):7279-7281.

139. Esfandiar A, Akhavan O, Irajizad A. Melatonin as a powerful bioantioxidant for reduction of graphene oxide. J Mater Chem. 2011; 21(29):10907-10914.

140. Gurunathan S, Han J, Kim JH. Humanin: a novel functional molecule for the green synthesis of graphene. Colloids Surf B Biointerfaces. 2013;111:376-383.

141. Deepak V, Umamaheshwaran PS, Guhan K, et al. Synthesis of gold and silver nanoparticles using purified URAK. Colloids Surf B Biointerfaces. 2011;86(2):353-358.

142. Vallhov H, Qin J, Johansson SM, et al. The importance of an endotoxin-free environment during the production of nanoparticles used in medical applications. Nano Lett. 2006;6(8):1682-1686.

143. Schinwald A, Murphy FA, Jones A, MacNee W, Donaldson K. Graphene-based nanoplatelets: a new risk to the respiratory system as a consequence of their unusual aerodynamic properties. ACS Nano. 2012;6(1):736-746.

144. Zhang YB, Ali SF, Dervishi E, et al. Cytotoxicity effects of graphene and single-wall carbon nanotubes in neural phaeochromocytomaderived PC12 cells. ACS Nano. 2010;4(6):3181-3186.

145. Bianco A. Graphene: safe or toxic? The two faces of the medal. Angew Chem Int Ed Engl. 2013;52(19):4986-4997.

146. Hu H, Yu J, Li Y, Zhao J, Dong H. Engineering of a novel pluronic F127/graphene nanohybrid for $\mathrm{pH}$ responsive drug delivery. J Biomed Mater Res A. 2012;100(1):141-148.

147. Mao HY, Chen W, Laurent S, et al. Hard corona composition and cellular toxicities of the graphene sheets. Colloids Surf B Biointerfaces. 2013;109:212-218.

148. Hu YM, Shamaei-Tousi A, Liu YJ, Coates A. A new approach for the discovery of antibiotics by targeting non-multiplying bacteria: a novel topical antibiotic for staphylococcal infections. PLoS One. 2010;5(7):e11818.

149. Liu SB, Hu M, Zeng TH, et al. Lateral dimension-dependent antibacterial activity of graphene oxide sheets. Langmuir. 2012;28(33): 12364-12372.

150. Santos CM, Mangadlao J, Ahmed F, Leon A, Advincula RC, Rodrigues DF. Graphene nanocomposite for biomedical applications: fabrication, antimicrobial and cytotoxic investigations. Nanotechnology. 2012;23(39):395101.

151. Li HH, Chen QS, Zhao JW, Urmila K. Enhancing the antimicrobial activity of natural extraction using the synthetic ultrasmall metal nanoparticles. Sci Rep. 2015;5:11033.

152. Ma JZ, Zhang JT, Xiong ZG, Yong Y, Zhao XS. Preparation, characterization and antibacterial properties of silver-modified graphene oxide. J Mater Chem. 2011;21(10):3350-3352.

153. de Faria AF, Martinez DS, Meira SM, et al. Anti-adhesion and antibacterial activity of silver nanoparticles supported on graphene oxide sheets. Colloids Surf B Biointerfaces. 2014;113:115-124.
154. Das MR, Sarma RK, Saikia R, Kale VS, Shelke MV, Sengupta P. Synthesis of silver nanoparticles in an aqueous suspension of graphene oxide sheets and its antimicrobial activity. Colloids Surf B Biointerfaces. 2011;83(1):16-22.

155. Chook SW, Chia CH, Zakaria S, et al. Antibacterial performance of Ag nanoparticles and AgGO nanocomposites prepared via rapid microwave-assisted synthesis method. Nanoscale Res Lett. 2012;7:541.

156. Cai X, Lin MS, Tan SZ, et al. The use of polyethyleneimine-modified reduced graphene oxide as a substrate for silver nanoparticles to produce a material with lower cytotoxicity and long-term antibacterial activity. Carbon. 2012;50(10):3407-3415.

157. Marambio-Jones C, Hoek EMV. A review of the antibacterial effects of silver nanomaterials and potential implications for human health and the environment. J Nanopart Res. 2010;12(5):1531-1551.

158. Le AT, Le TT, Phuong DT, et al. Synthesis of oleic acid-stabilized silver nanoparticles and analysis of their antibacterial activity. Mater Sci Eng C Mater Biol Appl. 2010;30(6):910-916.

159. Duran N, Marcato PD, De Conti R, Alves OL, Costa FTM, Brocchi M. Potential use of silver nanoparticles on pathogenic bacteria, their toxicity and possible mechanisms of action. J Brazil Chem Soc. 2010; 21(6):949-959.

160. Xu WP, Zhang LC, Li JP, et al. Facile synthesis of silver@graphene oxide nanocomposites and their enhanced antibacterial properties. J Mater Chem. 2011;21(12):4593-4597.

161. Nel A, Xia T, Madler L, Li N. Toxic potential of materials at the nanolevel. Science. 2006;311(5761):622-627.

162. Chang YL, Yang ST, Liu JH, et al. In vitro toxicity evaluation of graphene oxide on A549 cells. Toxicol Lett. 2011;200(3): 201-210.

163. Hu WB, Peng C, Lv M, et al. Protein corona-mediated mitigation of cytotoxicity of graphene oxide. ACS Nano. 2011;5(5):3693-3700.

164. Sasidharan A, Panchakarla LS, Chandran P, et al. Differential nanobio interactions and toxicity effects of pristine versus functionalized graphene. Nanoscale. 2011;3(6):2461-2464.

165. Chowdhury SM, Lalwani G, Zhang KV, Yang JY, Neville K, Sitharaman B. Cell specific cytotoxicity and uptake of graphene nanoribbons. Biomaterials. 2013;34(1):283-293.

166. Ali-Boucetta H, Bitounis D, Raveendran-Nair R, Servant A, Van den Bossche J, Kostarelos K. Purified graphene oxide dispersions lack in vitro cytotoxicity and in vivo pathogenicity. Adv Healthc Mater. 2013;2(3):433-441.

167. Lammel T, Boisseaux P, Fernandez-Cruz ML, Navas JM. Internalization and cytotoxicity of graphene oxide and carboxyl graphene nanoplatelets in the human hepatocellular carcinoma cell line Hep G2. Part Fibre Toxicol. 2013;10:27.

168. Qu GB, Liu SJ, Zhang SP, et al. Graphene oxide induces toll-like receptor 4 (TLR4)-dependent necrosis in macrophages. ACS Nano. 2013;7(7):5732-5745

169. Wang J, Sun P, Bao Y, Liu J, An L. Cytotoxicity of single-walled carbon nanotubes on PC12 cells. Toxicol In Vitro. 2011;25(1):242-250.

170. Chong Y, Ma YF, Shen H, et al. The in vitro and in vivo toxicity of graphene quantum dots. Biomaterials. 2014;35(19):5041-5048.

171. Jaworski S, Sawosz W, Kutwin M, et al. In vitro and in vivo effects of graphene oxide and reduced graphene oxide on glioblastoma. Int J Nanomed. 2015;10:1585-1596.

172. Li Y, Liu Y, Fu Y, et al. The triggering of apoptosis in macrophages by pristine graphene through the MAPK and TGF-beta signaling pathways. Biomaterials. 2012;33(2):402-411.

173. Sasidharan A, Panchakarla LS, Sadanandan AR, et al. Hemocompatibility and macrophage response of pristine and functionalized graphene. Small. 2012;8(8):1251-1263.

174. Liu JH, Yang ST, Wang HF, Chang YL, Cao AN, Liu YF. Effect of size and dose on the biodistribution of graphene oxide in mice. Nanomedicine (Lond). 2012;7(12):1801-1812.

175. Wang XJ, Podila R, Shannahan JH, Rao AM, Brown JM. Intravenously delivered graphene nanosheets and multiwalled carbon nanotubes induce site-specific Th2 inflammatory responses via the IL-33/ST2 axis. Int J Nanomed. 2013;8:1733-1748. 
176. Yang K, Wan J, Zhang S, Zhang Y, Lee ST, Liu Z. In vivo pharmacokinetics, long-term biodistribution, and toxicology of PEGylated graphene in mice. ACS Nano. 2011;5(1):516-522.

177. Duch MC, Budinger GRS, Liang YT, et al. Minimizing oxidation and stable nanoscale dispersion improves the biocompatibility of graphene in the lung. Nano Lett. 2011;11(12):5201-5207.

178. Zhang SA, Yang K, Feng LZ, Liu Z. In vitro and in vivo behaviors of dextran functionalized graphene. Carbon. 2011;49(12):4040-4049.

179. Wang X, Li JY, Qu WD, Chen G. Fabrication of graphene/poly(methyl methacrylate) composite electrode for capillary electrophoretic determination of bioactive constituents in Herba Geranii. J Chromatogr A. 2011;1218(32):5542-5548.

180. Yan L, Wang YP, Xu X, et al. Can graphene oxide cause damage to eyesight? Chem Res Toxicol. 2012;25(6):1265-1270.

181. Yang K, Wan JM, Zhang S, Tian B, Zhang YJ, Liu Z. The influence of surface chemistry and size of nanoscale graphene oxide on photothermal therapy of cancer using ultra-low laser power. Biomaterials. 2012;33(7):2206-2214

182. Singh SK, Singh MK, Nayak MK, et al. Thrombus inducing property of atomically thin graphene oxide sheets. ACS Nano. 2011;5(6) 4987-4996

183. Wen KP, Chen YC, Chuang CH, Chang HY, Lee CY, Tai NH. Accumulation and toxicity of intravenously-injected functionalized graphene oxide in mice. J Appl Toxicol. 2015;35(10):1211-1218.

184. Zhang D, Zhang ZY, Liu YY, et al. The short- and long-term effects of orally administered high-dose reduced graphene oxide nanosheets on mouse behaviors. Biomaterials. 2015;68:100-113.

185. Kim J, Choi KS, Kim Y, et al. Bioactive effects of graphene oxide cell culture substratum on structure and function of human adipose-derived stem cells. J Biomed Mater Res A. 2013;101(12):3520-3530.

186. Liu Y, Yu DS, Zeng C, Miao ZC, Dai LM. Biocompatible graphene oxide-based glucose biosensors. Langmuir. 2010;26(9):6158-6160.

187. Yan XB, Chen JT, Yang J, Xue QJ, Miele P. Fabrication of freestanding, electrochemically active, and biocompatible graphene oxide-polyaniline and graphene-polyaniline hybrid papers. ACS Appl Mater Interfaces. 2010;2(9):2521-2529.

188. Park S, Mohanty N, Suk JW, et al. Biocompatible, robust free-standing paper composed of a TWEEN/graphene composite. Adv Mater 2010;22(15):1736-1740.

189. Fan HL, Wang LL, Zhao KK, et al. Fabrication, mechanical properties, and biocompatibility of graphene-reinforced chitosan composites. Biomacromolecules. 2010;11(9):2345-2351.

190. Lee DY, Khatun Z, Lee JH, Lee YK, In I. Blood compatible graphene/ heparin conjugate through noncovalent chemistry. Biomacromolecules. 2011;12(2):336-341.

191. Lee WC, Lim CHYX, Shi H, et al. Origin of enhanced stem cell growth and differentiation on graphene and graphene oxide. ACS Nano. 2011;5(9):7334-7341.

192. Ruiz ON, Fernando KAS, Wang BJ, et al. Graphene oxide: a nonspecific enhancer of cellular growth. ACS Nano. 2011;5(10):8100-8107.

193. Chen GY, Pang DWP, Hwang SM, Tuan HY, Hu YC. A graphenebased platform for induced pluripotent stem cells culture and differentiation. Biomaterials. 2012;33(2):418-427.

194. Gurunathan S, Han JW, Eppakayala V, Dayem AA, Kwon DN, Kim JH. Biocompatibility effects of biologically synthesized graphene in primary mouse embryonic fibroblast cells. Nanoscale Res Lett. 2013;8:393.

195. Yang DH, Li T, Xu MH, et al. Graphene oxide promotes the differentiation of mouse embryonic stem cells to dopamine neurons Nanomedicine (Lond). 2014;9(16):2445-2455.

196. Dubey N, Bentini R, Islam I, Cao T, Neto AHC, Rosa V. Graphene: a versatile carbon-based material for bone tissue engineering. Stem Cells Int. 2015;2015:804213

197. Depan D, Girase B, Shah JS, Misra RDK. Structure-process-property relationship of the polar graphene oxide-mediated cellular response and stimulated growth of osteoblasts on hybrid chitosan network structure nanocomposite scaffolds. Acta Biomater. 2011;7(9): $3432-3445$.
198. Ryoo SR, Kim YK, Kim MH, Min DH. Behaviors of NIH-3T3 fibroblasts on graphene/carbon nanotubes: proliferation, focal adhesion, and gene transfection studies. ACS Nano. 2010;4(11):6587-6598.

199. Nayak TR, Andersen H, Makam VS, et al. Graphene for controlled and accelerated osteogenic differentiation of human mesenchymal stem cells. ACS Nano. 2011;5(6):4670-4678.

200. Kalbacova M, Broz A, Kong J, Kalbac M. Graphene substrates promote adherence of human osteoblasts and mesenchymal stromal cells. Carbon. 2010;48(15):4323-4329.

201. Akhavan O, Ghaderi E, Emamy H, Akhavan F. Genotoxicity of graphene nanoribbons in human mesenchymal stem cells. Carbon. 2013;54:419-431.

202. Akhavan O, Ghaderi E. Differentiation of human neural stem cells into neural networks on graphene nanogrids. J Mater Chem B. 2013; 1(45):6291-6301.

203. Li N, Zhang XM, Song Q, et al. The promotion of neurite sprouting and outgrowth of mouse hippocampal cells in culture by graphene substrates. Biomaterials. 2011;32(35):9374-9382.

204. Robinson JT, Tabakman SM, Liang YY, et al. Ultrasmall reduced graphene oxide with high near-infrared absorbance for photothermal therapy. J Am Chem Soc. 2011;133(17):6825-6831.

205. Huang YL, Tien HW, Ma CCM, et al. Effect of extended polymer chains on properties of transparent graphene nanosheets conductive film. J Mater Chem. 2011;21(45):18236-18241.

206. Tian B, Wang C, Zhang S, Feng LZ, Liu Z. Photothermally enhanced photodynamic therapy delivered by nano-graphene oxide. ACS Nano. 2011;5(9):7000-7009.

207. Zhang W, Guo ZY, Huang DQ, Liu ZM, Guo X, Zhong HQ. Synergistic effect of chemo-photothermal therapy using PEGylated graphene oxide. Biomaterials. 2011;32(33):8555-8561.

208. Yin D, Li Y, Lin H, et al. Functional graphene oxide as a plasmidbased Stat3 siRNA carrier inhibits mouse malignant melanoma growth in vivo. Nanotechnology. 2013;24(10):105102.

209. Arya N, Arora A, Vasu KS, Sood AK, Katti DS. Combination of single walled carbon nanotubes/graphene oxide with paclitaxel: a reactive oxygen species mediated synergism for treatment of lung cancer. Nanoscale. 2013;5(7):2818-2829.

210. Sheng ZH, Song L, Zheng JX, et al. Protein-assisted fabrication of nano-reduced graphene oxide for combined in vivo photoacoustic imaging and photothermal therapy. Biomaterials. 2013;34(21): 5236-5243.

211. Akhavan O, Ghaderi E. Graphene nanomesh promises extremely efficient in vivo photothermal therapy. Small. 2013;9(21):3593-3601.

212. Yang K, Feng LZ, Hong H, Cai WB, Liu Z. Preparation and functionalization of graphene nanocomposites for biomedical applications. Nat Protoc. 2013;8(12):2392-2403.

213. Kim H, Lee D, Kim J, Kim TI, Kim WJ. Photothermally triggered cytosolic drug delivery via endosome disruption using a functionalized reduced graphene oxide. ACS Nano. 2013;7(8):6735-6746.

214. Chen GY, Chen CL, Tuan HY, et al. Graphene oxide triggers toll-like receptors/autophagy responses in vitro and inhibits tumor growth in vivo. Adv Healthc Mater. 2014;3(9):1486-1495.

215. Wan H, Zhang Y, Liu ZY, et al. Facile fabrication of a near-infrared responsive nanocarrier for spatiotemporally controlled chemophotothermal synergistic cancer therapy. Nanoscale. 2014;6(15): 8743-8753.

216. Hong J, Shah NJ, Drake AC, et al. Graphene multilayers as gates for multi-week sequential release of proteins from surfaces. ACS Nano. 2012;6(1):81-88

217. Liu Z, Robinson JT, Sun XM, Dai HJ. PEGylated nanographene oxide for delivery of water-insoluble cancer drugs. $J \mathrm{Am}$ Chem Soc. 2008;130(33):10876-10877.

218. Zhang LM, Xia JG, Zhao QH, Liu LW, Zhang ZJ. Functional graphene oxide as a nanocarrier for controlled loading and targeted delivery of mixed anticancer drugs. Small. 2010;6(4):537-544.

219. Zheng XT, Li CM. Restoring basal planes of graphene oxides for highly efficient loading and delivery of beta-lapachone. Mol Pharm. 2012;9(3):615-621. 
220. Yang Y, Zhang YM, Chen Y, Zhao D, Chen JT, Liu Y. Construction of a graphene oxide based noncovalent multiple nanosupramolecular assembly as a scaffold for drug delivery. Chemistry. 2012;18(14): 4208-4215.

221. Wu J, Wang YS, Yang XY, et al. Graphene oxide used as a carrier for adriamycin can reverse drug resistance in breast cancer cells. Nanotechnology. 2012;23(35):355101.

222. Wate PS, Banerjee SS, Jalota-Badhwar A, et al. Cellular imaging using biocompatible dendrimer-functionalized graphene oxide-based fluorescent probe anchored with magnetic nanoparticles. Nanotechnology. 2012;23(41):415101.

223. Fan XJ, Jiao GZ, Zhao W, Jin PF, Li X. Magnetic Fe3O4-graphene composites as targeted drug nanocarriers for $\mathrm{pH}$-activated release. Nanoscale. 2013;5(3):1143-1152.

224. Miao W, Shim G, Kang CM, et al. Cholesteryl hyaluronic acid-coated, reduced graphene oxide nanosheets for anti-cancer drug delivery. Biomaterials. 2013;34(37):9638-9647.

225. Shi SX, Yang K, Hong H, et al. VEGFR targeting leads to significantly enhanced tumor uptake of nanographene oxide in vivo. Biomaterials. 2015;39:39-46.

226. Nair RR, Blake P, Blake JR, et al. Graphene as a transparent conductive support for studying biological molecules by transmission electron microscopy. Appl Phys Lett. 2010;97(15):153102.

227. Nelson T, Zhang B, Prezhdo OV. Detection of nucleic acids with graphene nanopores: ab initio characterization of a novel sequencing device. Nano Lett. 2010;10(9):3237-3242.

228. Heo C, Yoo J, Lee S, et al. The control of neural cell-to-cell interactions through non-contact electrical field stimulation using graphene electrodes. Biomaterials. 2011;32(1):19-27.

229. Wang Y, Li YM, Tang LH, Lu J, Li JH. Application of graphenemodified electrode for selective detection of dopamine. Electrochem Commun. 2009;11(4):889-892.

230. Dong XL, Cheng JS, Li JH, Wang YS. Graphene as a novel matrix for the analysis of small molecules by MALDI-TOF MS. Anal Chem. 2010;82(14):6208-6214.

231. Chang HX, Tang LH, Wang Y, Jiang JH, Li JH. Graphene fluorescence resonance energy transfer aptasensor for the thrombin detection. Anal Chem. 2010;82(6):2341-2346.

232. Wang Y, Shao YY, Matson DW, Li JH, Lin YH. Nitrogen-doped graphene and its application in electrochemical biosensing. ACS Nano. 2010;4(4):1790-1798.

233. Tang LH, Wang Y, Liu Y, Li JH. DNA-directed self-assembly of graphene oxide with applications to ultrasensitive oligonucleotide assay. ACS Nano. 2011;5(5):3817-3822.

234. Medintz IL, Uyeda HT, Goldman ER, Mattoussi H. Quantum dot bioconjugates for imaging, labelling and sensing. Nat Mater. 2005;4(6): 435-446.

235. Gao XH, Cui YY, Levenson RM, Chung LWK, Nie SM. In vivo cancer targeting and imaging with semiconductor quantum dots. Nat Biotechnol. 2004;22(8):969-976.

236. Choi JH, Burns AA, Williams RM, et al. Core-shell silica nanoparticles as fluorescent labels for nanomedicine. J Biomed Opt. 2007; 12(6):064007.

237. Welsher K, Liu Z, Daranciang D, Dai H. Selective probing and imaging of cells with single walled carbon nanotubes as near-infrared fluorescent molecules. Nano Lett. 2008;8(2):586-590.

238. Shen JH, Zhu YH, Chen C, Yang XL, Li CZ. Facile preparation and upconversion luminescence of graphene quantum dots. Chem Commun (Camb). 2011;47(9):2580-2582.

239. Chen WH, Yi PW, Zhang Y, Zhang LM, Deng ZW, Zhang ZJ. Composites of aminodextran-coated $\mathrm{Fe} 3 \mathrm{O} 4$ nanoparticles and graphene oxide for cellular magnetic resonance imaging. ACS Appl Mater Interfaces. 2011;3(10):4085-4091.

240. Sreejith S, Ma X, Zhao YL. Graphene oxide wrapping on squaraineloaded mesoporous silica nanoparticles for bioimaging. $J$ Am Chem Soc. 2012;134(42):17346-17349.
241. Qian J, Wang D, Cai FH, et al. Observation of multiphoton-induced fluorescence from graphene oxide nanoparticles and applications in in vivo functional bioimaging. Angew Chem Int Ed Engl. 2012;51(42):10570-10575.

242. Gollavelli G, Ling YC. Multi-functional graphene as an in vitro and in vivo imaging probe. Biomaterials. 2012;33(8):2532-2545.

243. Shi S, Yang K, Hong H, Barnhart TE, Liu Z, Cai W. Tumor vasculature targeting and imaging in living mice with reduced graphene oxide. Biomaterials. 2013;34(12):3002-3009.

244. Lalwani G, Henslee AM, Farshid B, et al. Two-dimensional nanostructure-reinforced biodegradable polymeric nanocomposites for bone tissue engineering. Biomacromolecules. 2013;14(3):900-909.

245. Cornelissen B, Able S, Kersemans V, et al. Nanographene oxide-based radioimmunoconstructs for in vivo targeting and SPECT imaging of HER2-positive tumors. Biomaterials. 2013;34(4):1146-1154.

246. Wang S, Zhang Q, Luo XF, et al. Magnetic graphene-based nanotheranostic agent for dual-modality mapping guided photothermal therapy in regional lymph nodal metastasis of pancreatic cancer. Biomaterials. 2014;35(35):9473-9483.

247. Gollavelli G, Ling YC. Magnetic and fluorescent graphene for dual modal imaging and single light induced photothermal and photodynamic therapy of cancer cells. Biomaterials. 2014;35(15): 4499-4507.

248. Zhang LN, Deng HH, Lin FL, et al. In situ growth of porous platinum nanoparticles on graphene oxide for colorimetric detection of cancer cells. Anal Chem. 2014;86(5):2711-2718.

249. Liu HY, Li L, Wang Q, Duan LL, Tang B. Graphene fluorescence switch-based cooperative amplification: a sensitive and accurate method to detection microRNA. Anal Chem. 2014;86(11):5487-5493.

250. Zhang H, Wu HX, Wang J, et al. Graphene oxide-BaGdF5 nanocomposites for multi-modal imaging and photothermal therapy. Biomaterials. 2015;42:66-77.

251. Yan XF, Niu G, Lin J, et al. Enhanced fluorescence imaging guided photodynamic therapy of sinoporphyrin sodium loaded graphene oxide. Biomaterials. 2015;42:94-102.

252. Meirelles LDS, Chagastelles PC, Nardi NB. Mesenchymal stem cells reside in virtually all post-natal organs and tissues. J Cell Sci. 2006;119(11):2204-2213.

253. Yang JY, Zhu ZH, Wang HF, Li FF, Du XL, Ma RLZ. Trop2 regulates the proliferation and differentiation of murine compact-bone derived MSCs. Int J Oncol. 2013;43(3):859-867.

254. Engler AJ, Sen S, Sweeney HL, Discher DE. Matrix elasticity directs stem cell lineage specification. Cell. 2006;126(4):677-689.

255. Dalby MJ, Gadegaard N, Tare R, et al. The control of human mesenchymal cell differentiation using nanoscale symmetry and disorder. Nat Mater. 2007;6(12):997-1003.

256. Pittenger MF, Mackay AM, Beck SC, et al. Multilineage potential of adult human mesenchymal stem cells. Science. 1999;284(5411): 143-147.

257. Yang K, Jung K, Ko E, et al. Nanotopographical manipulation of focal adhesion formation for enhanced differentiation of human neural stem cells. ACS Appl Mater Interfaces. 2013;5(21): 10529-10540.

258. Park SY, Park J, Sim SH, et al. Enhanced differentiation of human neural stem cells into neurons on graphene. Adv Mater. 2011;23(36): H263-H267.

259. Lu BG, Li T, Zhao HT, et al. Graphene-based composite materials beneficial to wound healing. Nanoscale. 2012;4(9):2978-2982.

260. Ku SH, Park CB. Myoblast differentiation on graphene oxide. Biomaterials. 2013;34(8):2017-2023.

261. Kanayama I, Miyaji H, Takita H, et al. Comparative study of bioactivity of collagen scaffolds coated with graphene oxide and reduced graphene oxide. Int J Nanomed. 2014;9:3363-3373.

262. Subbiah R, Du P, Van SY, et al. Fibronectin-tethered graphene oxide as an artificial matrix for osteogenesis. Biomed Mater. 2014;9(6): 065003 . 
263. Lee WC, Lim CH, Kenry, Su CL, Loh KP, Lim CT. Cell-assembled graphene biocomposite for enhanced chondrogenic differentiation. Small. 2015;11(8):963-969.

264. Chaudhuri B, Bhadra D, Moroni L, Pramanik K. Myoblast differentiation of human mesenchymal stem cells on graphene oxide and electrospun graphene oxide-polymer composite fibrous meshes: importance of graphene oxide conductivity and dielectric constant on their biocompatibility. Biofabrication. 2015;7(1):015009.
265. Luo Y, Shen H, Fang YX, et al. Enhanced proliferation and osteogenic differentiation of mesenchymal stem cells on graphene oxideincorporated electrospun poly(lactic-co-glycolic acid) nanofibrous mats. ACS Appl Mater Interfaces. 2015;7(11):6331-6339.

International Journal of Nanomedicine

\section{Publish your work in this journal}

The International Journal of Nanomedicine is an international, peerreviewed journal focusing on the application of nanotechnology in diagnostics, therapeutics, and drug delivery systems throughout the biomedical field. This journal is indexed on PubMed Central, MedLine, CAS, SciSearch $\AA$, Current Contents ${ }^{\circledR} /$ Clinical Medicine,
Journal Citation Reports/Science Edition, EMBase, Scopus and the Elsevier Bibliographic databases. The manuscript management system is completely online and includes a very quick and fair peer-review system, which is all easy to use. Visit http://www.dovepress.com/ testimonials.php to read real quotes from published authors.

Submit your manuscript here: http://www.dovepress.com/international-journal-of-nanomedicine-journal 